OPEN ACCESS

Edited by:

Lia Rimondini,

University of Eastern Piedmont, Italy

Reviewed by:

Cinzia Giannini,

Italian National Research Council, Italy Marta Miola

Politecnico di Torino, Italy

${ }^{*}$ Correspondence: Simone Sprio simone.sprio@istec.cnr.it

Specialty section: This article was submitted to Biomaterials,

a section of the journal

Frontiers in Materials

Received: 24 March 2020 Accepted: 22 June 2020 Published: 28 July 2020

Citation:

Sprio S, Dapporto M, Preti L, Mazzoni E, laquinta MR, Martini F, Tognon M, Pugno NM, Restivo E,

Visai $L$ and Tampieri A (2020)

Enhancement of the Biological and Mechanical Performances

of Sintered Hydroxyapatite by Multiple Ions Doping. Front. Mater. 7:224 doi: 10.3389/fmats.2020.00224

\section{Enhancement of the Biological and Mechanical Performances of Sintered Hydroxyapatite by Multiple lons Doping}

\author{
Simone Sprio ${ }^{1 *}$, Massimiliano Dapporto ${ }^{1}$, Lorenzo Preti ${ }^{1}$, Elisa Mazzoni ${ }^{2}$, \\ Maria Rosa laquinta ${ }^{2}$, Fernanda Martini' ${ }^{2}$, Mauro Tognon ${ }^{2}$, Nicola M. Pugno ${ }^{3,4}$, \\ Elisa Restivo ${ }^{5,6}$, Livia Visai $^{1,5,6}$ and Anna Tampieri ${ }^{1}$ \\ 1 Institute of Science and Technology for Ceramics-National Research Council (ISTEC-CNR), Faenza, Italy, ${ }^{2}$ Department \\ of Medical Sciences, University of Ferrara, Ferrara, Italy, ${ }^{3}$ Laboratory of Bio-Inspired, Bionic, Nano, Meta Materials \& \\ Mechanics, Department of Civil, Environmental and Mechanical Engineering, University of Trento, Trento, Italy, ${ }^{4}$ School of \\ Engineering and Materials Science, Queen Mary University of London, London, United Kingdom, ${ }^{5}$ Biochemistry Unit, \\ Department of Molecular Medicine, Center for Health Technologies (CHT), UdR INSTM, University of Pavia, Pavia, Italy, \\ ${ }^{6}$ Department of Occupational Medicine, Toxicology and Environmental Risks, Istituti Clinici Scientifici (ICS) Maugeri S.p.A, \\ IRCCS, Pavia, Italy
}

In the present work, hydroxyapatite (HA) nanoparticles doped with $\mathrm{Mg}^{2+}, \mathrm{Sr}^{2+}$, and $\mathrm{Zn}^{2+}$ ions are developed by wet neutralization method and then sintered at $1,250^{\circ} \mathrm{C}$ to obtain bulk consolidated materials. Physicochemical and microstructural analyses show that the presence of doping ions in the HA structure induced the formation of $\beta T C P$ as secondary phase, during the sintering process, and we found that this effect is depending on the stability of the various doping ions in the hydroxyapatite lattice itself. We also found that the formation of $\beta$ TCP as secondary phase, in turn, confines the grain growth of HA induced by the high-temperature sintering process, thus leading to a strong increase of the flexural strength of the bulk materials, according to Hall-Petchlike law. Furthermore, we found that the doping ions enter also in the structure of the $\beta$ TCP phase; besides the grain growth confinement, also the solubility and ion release ability of the final materials were enhanced. In addition to ameliorate the mechanical performance, the described phenomena also activate multiple biofunctionalities: (i) ability to upregulate various genes involved in the osteogenesis, as obtained by human adipose stem cells culture and evaluated by array technology; (ii) enhanced resistance to the adhesion and proliferation of Gram+ and Gram- bacterial strains. Hence, our results open a perspective for the use of sintered multiple ion-doped HA to develop ceramic biodevices, such as plates, screws, or other osteosynthesis media, with enhanced strength, osteointegrability, and the ability to prevent post-surgical infections.

Keywords: calcium phosphates, ion doping, osteogenic properties, antibacterial properties, mechanical properties, magnesium, strontium, zinc

\section{INTRODUCTION}

Since decades, extensive research is being engaged for the development of synthetic biodevices with improved biological and mechanical functionality, suitable for application in bone surgery (Munch et al., 2008; Dutta et al., 2015). Particularly, the development of fixation devices as osteosynthesis media capable of enhanced osteointegrability and mechanical properties is highly desired, to 
support the stabilization of complex fractures or the fixation of bone implants (Suryavanshi et al., 2016). In spite of their wide use in orthopedics as fixation media (Goodrich et al., 2012), metallic implants can undergo failure due to infections, corrosion, fatigue, and poor osteointegrability, all factors jeopardizing the healing process (Pohler, 2002; Ribeiro et al., 2012). Particularly, mechanical mismatch between the implant and surrounding bone can result in the implant loosening and bone resorption (Alexander and Theodos, 1993; Sheikh et al., 2015). On the other hand, the occurrence of postsurgical infections is a major concern, also due to the antibiotic resistance of various bacterial strains, a phenomenon that is constantly growing and that will become, more and more, a primary cause of failure of surgical interventions, particularly in orthopedics (Li and Webster, 2018; Hofer, 2019). To overcome these drawbacks, a growing literature is investigating the possibility of developing biomaterials capable to establish tight bone-implant interfaces thanks to improved mechanical properties and to superior osteointegrative and anti-infective ability. Previous studies investigated the possibility of achieving materials with inherent antibacterial properties as induced by the surface composition and/or micro-texture (Albers et al., 2013; Slavin et al., 2017). In this respect, hydroxyapatite [HA: $\left.\mathrm{Ca}_{5}\left(\mathrm{PO}_{4}\right)_{3}(\mathrm{OH})\right]$ is since decades considered as elective material for application in bone surgery, thanks to its compositional similarity with the mineral component of bone, even though the relatively poor mechanical properties pose concerns on its use (Polo-Corrales et al., 2014; Eliaz and Metoki, 2017). It is also known that controlled ion substitutions in the structure of HA, attempting to more closely mimic the mineral composition of natural bone, increase its bioactivity and bone-forming ability (Cazalbou et al., 2005; Ballardini et al., 2018; Sprio et al., 2019). Particularly, $\mathrm{Mg}^{2+}$ is recognized to promote the formation of new bone mineral nuclei, particularly active in the newly formed bone tissue (Bigi et al., 1992). $\mathrm{Mg}^{2+}$ ions, as well as $\mathrm{Sr}^{2+}$ and also $\mathrm{Zn}^{2+}$, are known as active regulators of osteoblasts and osteoclast cells, thus able to modulate the bone turnover, potentially effective also in the case of osteoporotic bones (Boanini et al., 2010). Recent studies report that the multiple doping of HA with these ions can also promote inherent antiinfective properties (Ballardini et al., 2018; Sprio et al., 2019), thus being promising for the development of new medical devices with enhanced bioactivity and osteointegrability while preventing adverse infective complications, at the same time. These studies were carried out on as-synthesized HA powders. However, the development of $3 \mathrm{D}$ ceramic devices with relevant mechanical properties requires the use of sintering process for their consolidation. While several investigations of the effects of doping ions have been carried out on nanocrystalline and nanostructured HAs obtained by low temperature wet synthesis, there are very few studies investigating the biological effect of these ions in sintered ceramics, but they are limited to calcium silicate phases (Wu et al., 2007; Zreiqat et al., 2010; Liu et al., 2019). In particular, in spite of the urging need of implantable biodevices capable of counteracting the formation of biofilms, studies on the antibacterial ability of ion-doped sintered CaPs have not yet been reported.
In this work, various multi-substituted HAs were synthesized by a wet neutralization process and sintered at high temperature to obtain consolidated ceramic materials. The study highlights the effect of the various substituting ions, such as $\mathrm{Mg}^{2+}$, $\mathrm{Sr}^{2+}$, and $\mathrm{Zn}^{2+}$, on the physico-chemical, morphological, and mechanical properties as well as on the biological abilities of the resulting sintered ceramics, as obtained by cellular epigenetic tests and microbiological analyses conducted on Escherichia coli and Staphylococcus aureus, which are among the most common infective strains responsible of post-operative complications in orthopedics.

\section{MATERIALS AND METHODS}

\section{Synthesis of the Ion-Doped Apatites}

A neutralization reaction was established between an aqueous suspension of calcium hydroxide $\left[\mathrm{Ca}(\mathrm{OH})_{2}\right.$, Sigma Aldrich, $95 \%$ purity], and a solution of phosphoric acid $\left(\mathrm{H}_{3} \mathrm{PO}_{4}\right.$, Fluka, $85 \%$ purity). To introduce foreign ions in the final product, $\mathrm{Mg}^{2+}, \mathrm{Sr}^{2+}, \mathrm{Zn}^{2+}$ cations were added in the aqueous calcium suspension, as magnesium chloride $\left(\mathrm{MgCl}_{2}\right.$, Sigma Aldrich), strontium chloride $\left(\mathrm{SrCl}_{2}\right.$, Sigma Aldrich), and zinc chloride $\left(\mathrm{ZnCl}_{2}\right.$, Sigma Aldrich). The initial $\mathrm{Ca} / \mathrm{P}$ ratio was set to 1.67 , that is, equal to that of stoichiometric HA.

The reaction is conducted in a round-bottomed flask, filled with an aqueous suspension of calcium hydroxide, containing the salts of the doping cations and kept at $37^{\circ} \mathrm{C}$, under mechanical stirring. The neutralization process was conducted by slowly adding $\mathrm{H}_{3} \mathrm{PO}_{4}$ solution to the alkaline suspension (dripping rate $=1 \mathrm{drop} / \mathrm{s}$ ). At the end of the process, the suspension is left in agitation at $37^{\circ} \mathrm{C}$ for $2 \mathrm{~h}$, then left to mature overnight at room temperature. Then, the suspension is washed with bi-distilled water for three times, in order to eliminate ions simply adsorbed on the HA surface and then dried at $40^{\circ} \mathrm{C}$ in oven. Finally, the obtained powder is sieved at $150 \mu \mathrm{m}$.

In the present work, four different sets of ion-doped HA powders were synthesized, the first set includes non-doped HA, as reference material (coded as HA), HA doped with magnesium (MgHA), HA doped with magnesium and strontium (MgSrHA), and HA doped with magnesium and zinc (MgZnHA). The symbols $\mathrm{X}_{M g}, \mathrm{X}_{S r}$, and $\mathrm{X}_{Z n}$ indicates the initial molar fraction, respectively, of $\mathrm{Mg}^{2+}, \mathrm{Sr}^{2+}$, and $\mathrm{Zn}^{2+}$, calculated as $\frac{\text { mole of } X X}{\text { mole of } \mathrm{Ca}}$. 100 , where $X X$ indicates $\mathrm{Mg}, \mathrm{Sr}$ or $\mathrm{Zn}$.

\section{Development of Sintered Calcium Phosphate Materials}

Consolidated ceramics were obtained by thermal sintering of the as-synthesized powders at $1,250^{\circ} \mathrm{C}$ for $1 \mathrm{~h}$ in a muffle furnace. The sintering was carried out on pellets obtained by uniaxial pressing $1.5 \mathrm{~g}$ of apatite powders in a steel mold (20 $\mathrm{mm}$ in diameter) at 700 bar. The resulting pellets were then further treated by cold isostatic pressing at 2,500 bar, to obtain green ceramic bodies with maximal relative density, suitable to obtain the highest degree of densification in the final sintered bodies. The sintered bodies 
are henceforth coded as follows: S-HA, S-MgHA, S-MgSrHA, S-MgZnHA.

\section{Physico-Chemical Characterization}

The crystalline phase composition of the as-obtained and sintered materials was obtained by X-ray diffraction (XRD) with a D8 ADVANCE (Bruker, Karlsruhe, Germany) diffractometer using $\mathrm{Cu} \mathrm{K} \alpha$ radiation $(\lambda=1.54178 \AA)$ generated at $40 \mathrm{kV}$ and $40 \mathrm{~mA}$, a counting time of $0.5 \mathrm{~s}$, and a step size of $0.02^{\circ} 2 \theta$. Semiquantitative analysis and the evaluation of the cell parameters and domain size of the crystalline structures were performed by full profile analysis of the XRD spectra, using the software TOPAS 5 (Bruker, Karlsruhe, Germany). The experimental XRD spectra were analyzed in reference to previously published crystal structure models. In all the experiments the background was modeled with an 11th-order Chebyshev polynomial. The calculation was carried out, up to convergence, by refining the scale factor, the domain size and the cell parameters at the same time. The domain size was evaluated keeping into account the contribution of the instrumental resolution function, obtained by fitting the diffraction pattern of $\mathrm{a} \mathrm{LaB}_{6}$ NIST standard (Giannini et al., 2016).

The chemical analysis of the as-obtained apatite powders was performed on dried samples $(20 \mathrm{mg})$ using ICP-OES spectrometer (Agilent 5100, United States) and primary standards (1,000 ppm, Fluka). The samples were dissolved into $2 \mathrm{ml}$ of nitric acid then diluted in $100 \mathrm{ml}$ of milliQ water.

\section{Characterization of the Sintered Bodies}

Field emission gun scanning electron microscopy (FEG-SEM) (Sigma NTS GmbH, Carl Zeiss, Oberkochen, Germany) was used to evaluate the morphology of the final material at the multiscale. The samples were placed on an aluminum stub and covered with a thin layer of gold to improve conductivity. The analysis of the microstructure was carried out by mirror-polishing and a subsequent acid attack with $\mathrm{HCl} 1 \mathrm{M}$ for $5 \mathrm{~s}$ to put in evidence the grain boundaries. The equipment used is Sigma NTS GmbH (Carl Zeiss, Oberkochen, Germany).

\section{Mechanical Characterization}

The compression and flexural strength of sintered bodies was evaluated with a universal testing machine (MTS Insight 5, Eden Prairie, MN, United States), crosshead speed $2 \mathrm{~mm} / \mathrm{min}$, on five sintered samples for each investigated material. For compression tests, the samples were obtained in form of cylinders with a diameter of $10 \mathrm{~mm}$ and height of $15 \mathrm{~mm}$. Flexural tests were carried out by 4-point bending on parallelepipeds, with $25.0 \mathrm{~mm} \times 2.5 \mathrm{~mm} \times 2.0 \mathrm{~mm}$ in size. Nanoindentation tests were carried out on mirror-polished sintered samples (iNano, Nanomechanics, Inc., United States). A Berkovich indenter was used to perform indentations up to a maximum load of $45 \mathrm{mN}$, so that hardness and Young's moduli could be obtained.

\section{Ion Release Tests}

The evaluation of the ion release with time was made by immersing tablets ( $1 \mathrm{~g}$ of powder each) into $5 \mathrm{ml}$ of $\mathrm{pH}=7.4$ buffer solution (Ca- and Mg-free Hank's Balanced Salt solution) and maintained at $37^{\circ} \mathrm{C}$ under gentle shaking. At scheduled times (i.e., after 1, 2, 3, 7, 11, and 15 days) the solution was removed and $5 \mathrm{ml}$ of fresh solution was added to the tablets. The liquids containing the ions released after the prefixed times were analyzed by ICP-OES for the quantitative determination of $\mathrm{Ca}$, $\mathrm{Mg}$, and $\mathrm{Zn}$. The results were presented as cumulative data. All the experiments were made in triplicate.

\section{Cells and Cell Culture}

Human adipose-derived mesenchymal stem cells (hASC) were purchased from Lonza Milan, Italy (Catalog n. PT-5006) as cryopreserved frozen cells at the first passage. These cells are positive for surface markers CD13, CD29, CD44, CD73, CD90, CD105, CD166, while are negative for other markers, such as CD14, CD31, CD45 (Mazzoni et al., 2020). Cells were expanded in Dulbecco's Modified Eagle Medium F-12 (DMEM/F12; Lonza, Milan, Italy), supplemented with $10 \%$ fetal bovine serum (FBS) and $10 \%$ antibiotics (Pen/Strep $10.000 \mathrm{U} / \mathrm{ml}$ ) at a density of 5,000 cells $/ \mathrm{cm}^{2}$, in a T75 flask (Falcon BD, Franklin Lakes, NJ, United States) at $37^{\circ} \mathrm{C}$ with $5 \% \mathrm{CO}_{2}$ in a humidified atmosphere (Manfrini et al., 2013; Mazzoni et al., 2017, 2020). At the second passage, hASCs were randomly assigned to five treatment groups: hASCs grown in monolayer in 24-well tissue culture polystyrene plates (TCP) and hASCs grown on biomaterials, such as (i) S-HA, (ii) S-MgHA, (iii) S-MgSrHA, (iv) S-MgZnHA. In biomaterial groups, the samples were placed separately in 24-well plates $(\varnothing=10 \mathrm{~mm})$ to cover the surface area. hASC cultures were then filled with $200 \mu \mathrm{l}$ cell suspension containing $10^{4}$ cells for each sample and incubated for $2 \mathrm{~h}$ (Mazzoni et al., 2017). The cell suspension was subjected to gentle shaking every $15 \mathrm{~min}$ in order to maximize cell-material interaction. Plates were incubated at $37^{\circ} \mathrm{C}$. in humidified air $\left(5 \% \mathrm{CO}_{2}\right)$ until the time of the assay. $\mathrm{RT}^{2}$ Profiler ${ }^{\mathrm{TM}}$ PCR Array was performed at day 14 (Mazzoni et al., 2020).

\section{RNA Isolation and $\mathbf{R T}^{2}$ Profiler $^{\mathrm{TM}}$ PCR Array Analyses of Extracellular Matrix and Adhesion Molecule Genes}

To profile the expression of 84 Osteogenesis-related genes simultaneously we used the Human Osteogenesis $\mathrm{RT}^{2}$ Profiler PCR Array Catalog number PAHS-026Z and product n. 330231 (Qiagen Milan, Italy) ${ }^{1}$. The Human Osteogenesis $\mathrm{RT}^{2}$ Profiler PCR was performed according to the manufacturer's instructions. The list of genes was reported in the product and the primers set used is covered by the patent of this product.

To identify of the extracellular matrix (ECM) and adhesion molecule expression genes activated by the studied materials, $\mathrm{RT}^{2}$ Profiler PCR Array profiles was performed in hASCs grown on selected biomaterials, reported above. Human ASCs were grown on biomaterials and plastic plates employed as the control (TCPS) until day 14. After this period, total RNA was extracted through RNeasy Plus Micro Kit (Qiagen, Milan, Italy) according to the manufacturer's instructions

\footnotetext{
${ }^{1}$ https://geneglobe.b2b-qiagen.com/product-groups/rt2-profiler-pcr-arrays
} 
(Mazzoni et al., 2020). RNA quality and quantity were assessed using a Nanodrop spectrophotometer (ND-1000, NanoDrop Technologies, Wilmington, DE, United States) and stored at $80^{\circ} \mathrm{C}$ until the time of the analysis (Mazzoni et al., 2012). Purified RNA from hASCs grown on selected biomaterials and TCPS was reverse transcribed to cDNA using the $\mathrm{RT}^{2}$ First Strand CDNA Kit (Qiagen, Milan, Italy). RT $^{2}$ Profiler PCR Array (Qiagen, Milan, Italy Catalog n. PAHS-013Z) was used to analyze the expression of 84 genes for human ECM, cell adhesion molecules, and five housekeeping genes, at day 14 (Mazzoni et al., 2017). Specific primers sets employed in real-time PCRs were used to analyze the expression of 84 genes codified for proteins involved in cell-to-cell adhesion, cells to the ECM adhesion, and ECM proteins, such as collagens and ECM protease. $\mathrm{RT}^{2}$ Profiler $\mathrm{PCR}^{\mathrm{TM}}$ Array PCR ${ }^{\mathrm{TM}}$ was performed using SYBR Green method on a CFX96 Touch PCR detection system (Bio-Rad, Milan, Italy) (Mazzoni et al., 2017). In terms of data analysis, fold-changes of each gene expression were calculated using the $2^{-\Delta} \Delta C T$ method, whereas the housekeeping genes employed as controls were used to normalize the results (Mazzoni et al., 2017, 2020). Two independent experiments were performed simultaneously. Positive values indicated individual upregulated genes, while negative values indicated the downregulated genes, compared to controls. Only twice fold up- or downregulated expression ( $\log _{2}$ fold change $<1$ or $>1$ ) was considered significant, whereas a onefold change meant that the same amount of analyzed gene was expressed in cells adherent to the biomaterials when compared to those grown on the polystyrene vessel, the control.

\section{Bacterial Strains and Culture Conditions}

The microorganisms used in this study were Escherichia coli ATCC 25922 (E. coli), and Staphylococcus aureus ATCC 25923 (S. aureus), kindly supplied by R. Migliavacca (Department of Clinical Surgical, Diagnostic and Pediatric Sciences, University of Pavia, Italy). Both the bacteria strains were routinely grown in their culture medium overnight under aerobic conditions at $37^{\circ} \mathrm{C}$ using a shaker incubator (Asal Srl, Italy): E. coli in Luria Bertani Broth (LB) (Difco, Detroit, MI, United States) and S. aureus in Brain Heart Infusion (BHI) (Difco). Both these cultures were statically incubated at $37^{\circ} \mathrm{C}$ under aerobic conditions and reduced to a final density of $1 \times 10^{10}$ cells $/ \mathrm{mL}$ as determined by comparing the optical density $\left(\mathrm{OD}_{600}\right)$ of the sample with a standard curve relating $\mathrm{OD}_{600}$ to cell number (Bari et al., 2017).

\section{Bacterial Viability}

All types of ions-doped HA samples were washed in sterile phosphate buffer saline (PBS $1 \times$ ) and directly incubated with $200 \mu \mathrm{L}\left(1 \times 10^{5}\right)$ E. coli or $S$. aureus cell suspensions for $24 \mathrm{~h}$ at $37^{\circ} \mathrm{C}$, respectively. At the end of the incubation time, an MTT [3-(4,5-dimethylthiazol-2-yl)-2,5-diphenyltetrazolium bromide; Sigma-Aldrich ${ }^{\circledR}$, United States] test was performed on the following samples: (1) the planktonic bacterial cultures after their removal from the ions-doped HA materials; and (2) directly on the ions-doped HA materials used for the bacterial incubation. The same aliquot of bacteria was also cultured in a Tissue Culture Plate (TCP) used as a positive control. After $3 \mathrm{~h}$ of incubation at $37^{\circ} \mathrm{C}$, the MTT reaction was stopped by adding $100 \mu \mathrm{L}$ of solution $\mathrm{C}$ (2-propanol, $\mathrm{HCl} 0.04 \mathrm{~N}$ ) and further incubated for $15 \mathrm{~min}$ at $37^{\circ} \mathrm{C}$. The colorimetric reaction was read at CLARIOstar (BMG Labtech, Germany) at $570 \mathrm{~nm}$ wavelength with $630 \mathrm{~nm}$ as the reference wavelength. Results were firstly normalized to TCP and then to S-HA (undoped HA) set as $100 \%$. The experiments were performed in duplicate and repeated three times.

\section{Confocal Laser Scanning Microscopy (CLSM) Studies}

As previously reported (Pallavicini et al., 2017) for confocal studies, $0.2 \mathrm{~mL}\left(1 \times 10^{5}\right)$ of both E. coli and S. aureus suspensions were dispensed into 48-well microplates (Costar) containing on the bottom sterile ions-doped HA materials and incubated for $24 \mathrm{~h}$ at $37^{\circ} \mathrm{C}$. After $24 \mathrm{~h}$, the bacteria cultures were gently removed and the viability of adherent bacteria was estimated with the BacLight Live/Dead viability kit (Molecular Probes, Eugene, OR, United States). The kit includes two fluorescent nucleic acid stains: SYTO9 and propidium iodide. SYTO9 penetrates both viable and non-viable bacteria, while propidium iodide penetrates bacteria with damaged membranes and quenches SYTO9 fluorescence. Dead bacteria, which take up propidium iodide, fluoresce red, and bacteria fluorescing green, are deemed viable. For assessing viability, $1 \mu \mathrm{L}$ of the stock solution of each stain was added to $3 \mathrm{~mL}$ of PBS $1 \times$ and, after being mixed, $200 \mu \mathrm{L}$ of the solution was dispensed into 48 -well microplates containing the apatite samples and incubated at $22^{\circ} \mathrm{C}$ for $15 \mathrm{~min}$ in the dark. Stained bacteria were examined under a Leica CLSM (model TCS SP8 DLS; Leica, Wetzlar, Germany) using a $40 \times$ and $63 \times$ oil immersion objective. The excitation and emission wavelengths used for detecting SYTO9 were 488 and $525 \mathrm{~nm}$, respectively. Propidium iodide was excited at $520 \mathrm{~nm}$, and its emission was monitored at $620 \mathrm{~nm}$. The optical sections of $0.9 \mu \mathrm{m}$ were collected over the complete thickness of the sample, and for each sample, images from three randomly selected positions were acquired. The $3 \mathrm{D}$ projections were obtained using software LAS X.

\section{Statistical Analysis}

All the statistical calculations related to antibacterial tests were carried out using GraphPad Prism 5.0 (GraphPad Inc., San Diego, CA, United States). Statistical analysis was performed using Student's unpaired, two-sided $t$-test and through one-way variance analysis (ANOVA), followed by Bonferroni post hoc, for multiple comparisons (significance level of $p \leq 0.05$ ).

\section{RESULTS}

\section{Physicochemical and Morphological Characterization of the As-Synthesized Apatites}

The as-obtained powders are all composed of $\mathrm{HA}$ as a single crystalline phase (Figure 1). The broad profile of the obtained diffraction patterns can be ascribed to low crystallinity, as induced by the powder synthesis carried out at body temperature 


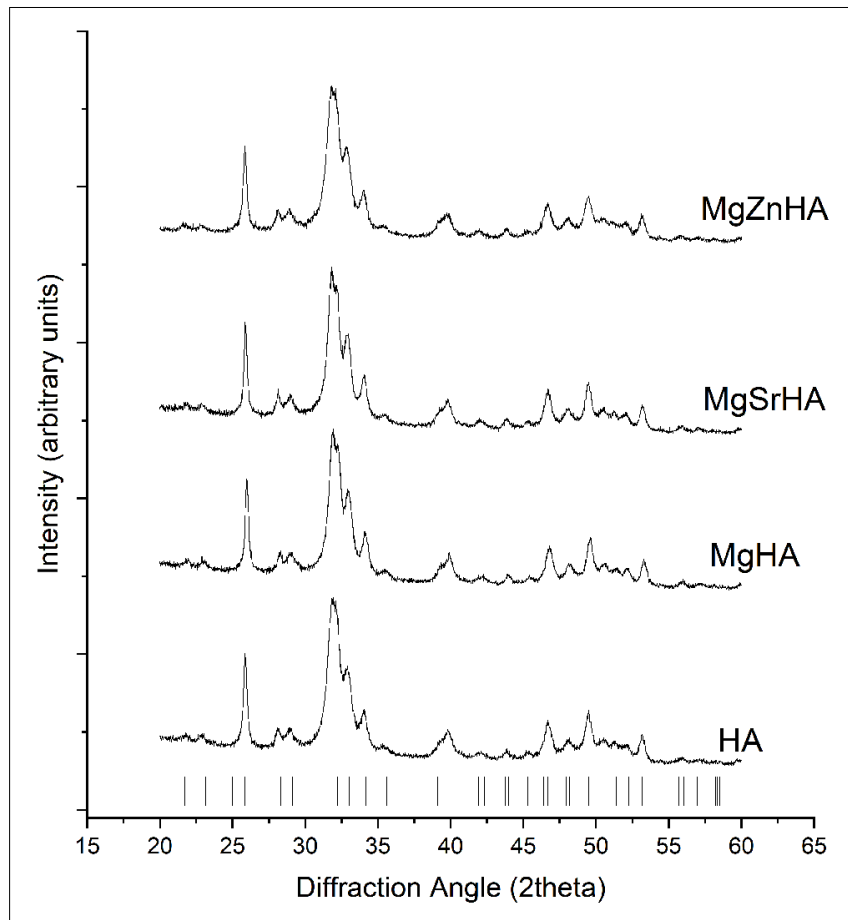

FIGURE 1 | XRD spectra of the as-synthesized powders. The markers point to $X R D$ reflections of the $H A$ structure.

and by the incorporation of doping ions in the apatitic structure (Sprio et al., 2008). The chemical analysis by ICP (Table 1) reports that only a fraction of the foreign ions initially present in the reaction vessel was actually incorporated into the HA structure, whereas the remaining was eliminated during the powder washing.

The cell parameters and volume, and the average size of crystalline domains in the as-obtained HA powders are reported in Table 2. All the as-synthesized apatites show very small domain size $\left(D_{a v}\right)$, ascribed to the low synthesis temperature that limited the crystal growth. Changes in cell parameters and volume of the HA crystal can be related to different ionic radii of doping cations (here $\mathrm{Mg}^{2+} \approx 66 \mathrm{pm}, \mathrm{Sr}^{2+} \approx 112 \mathrm{pm}$ or $\mathrm{Zn}^{2+} \approx 74 \mathrm{pm}$ ) substituting $\mathrm{Ca}^{2+}(\approx 99 \mathrm{pm})$, which influence the interatomic distances (Procopio et al., 2019). It was reported that $\mathrm{Mg}^{2+}$ has limited ability to substitute $\mathrm{Ca}^{2+}$ in large extent, ascribed to its much smaller ionic radius (Boanini et al., 2010). However, in the single-doped MgHA, we can observe a very little decrease of the $c$ axis and of the overall cell volume, in comparison with the undoped HA, in agreement with a previous study (Tampieri et al., 2004), thus suggesting that in the MgHA sample at least a fraction of the introduced $\mathrm{Mg}^{2+}$ could substitute $\mathrm{Ca}^{2+}$ in the HA lattice. Concerning the multi-doped apatites, during the formation of the HA crystal a competition is established between $\mathrm{Mg}^{2+}-\mathrm{Sr}^{2+}$ (in $\mathrm{MgSrHA}$ ) or $\mathrm{Mg}^{2+}-\mathrm{Zn}^{2+}$ ions (in $\mathrm{MgZnHA}$ ) attempting to enter the $\mathrm{Ca}^{2+}$ crystal sites, thus making difficult to correlate crystal data with the extent of specific ion occupancy in the apatite crystal sites. As an overall effect, the analysis of the crystal data reports a small increase of the cell volume in $\mathrm{MgSrHA}$, ascribed to partial substitution of $\mathrm{Ca}^{2+}$ with the larger $\mathrm{Sr}^{2+}$ ions, and a small reduction in $\mathrm{MgZnHA}$, due to the smallest size of both $\mathrm{Mg}^{2+}$ and $\mathrm{Zn}^{2+}$ ions.

Microscopic observation by SEM (Figure 2) shows that the as-obtained HA powders are made of primary rounded particles with size of few tens of nanometers, agglomerated in micronsize clusters, due to their high specific surface that enhance electrostatic interactions.

\section{Physicochemical Characterization of the Sintered Apatites}

The sintering of the HA powders was carried out on uniaxially pressed pellets at $1,250^{\circ} \mathrm{C}$ for $1 \mathrm{~h}$. The XRD analysis of the sintered materials shows that S-HA, prepared using the undoped $\mathrm{HA}$ as a raw material, is composed of $\mathrm{HA}$ as single phase and traces of calcium oxide $(\mathrm{CaO})$ (Figure 3). Conversely, in the samples prepared with ion-doped apatites, different amounts of $\beta$ TCP phase are found. Besides, magnesium oxide $(\mathrm{MgO})$ is also found in trace amounts. No other oxides or secondary phases involving $\mathrm{Sr}^{2+}$ or $\mathrm{Zn}^{2+}$ ions are found. Table 3 also shows that the composition of the HA phase in the S-HA sample is nearly stoichiometric $(\mathrm{Ca} / \mathrm{P}$ ratio $\sim 1.67)$, accounting for the trace amount of $\mathrm{CaO}$ found as a secondary phase. The doped materials show reduced $\mathrm{Ca} / \mathrm{P}$ ratio as an effect of the calcium deficiency related to the incorporation of doping divalent cations in calcium crystal sites.

Table 3 shows that the concentration of $\mathrm{Sr}^{2+}$ and $\mathrm{Zn}^{2+}$ in the sintered materials is very close to the values found in the assynthesized apatite powders (see also Table 1). Conversely, a quite reduced amount of $\mathrm{Mg}^{2+}$ is found, particularly in S-MgZnHA sample, suggesting that it could be partially evaporated during the high-temperature sintering process. This is reasonable considering that the boiling point of magnesium is $\sim 1,090^{\circ} \mathrm{C}$, that is, lower than the sintering temperature adopted in our work.

The full profile analysis of the XRD spectra was carried out by using TOPAS 5 software and previously published crystal models of HA, $\beta$ TCP, $\mathrm{MgO}$, and $\mathrm{CaO}$ phases (Sasaki et al., 1979; Rodríguez-Lorenzo et al., 2003; Yashima et al., 2003). In every calculation run we refined simultaneously the scale factor, cell parameters and domain size of all the phases present in the sample, until convergence, thus finally obtaining also a semiquantitative estimation of the crystalline structures content. We observe slight variations in cell parameters of the HA phase present in the doped sintered bodies, but a marked decrease of the domain size $\left(D_{a v}\right)$, in respect to the undoped S-HA (Table 4). Ion-doped apatite phases are well-known for their reduced thermodynamic stability, compared to the stoichiometric phase. Thus, the thermal treatment yielded the segregation of foreign ions outside the HA lattice and induced the decomposition of the initial apatite phase followed by the formation of $\beta$ TCP phase at the grain boundaries that could have interfered with the growth of the HA crystals and limit the final size. Whereas $\mathrm{Mg}^{2+}$ can be assumed to be completely expelled from the HA lattice during sintering, it is possible that some substitution of $\mathrm{Ca}^{2+}$ with $\mathrm{Sr}^{2+}$ or $\mathrm{Zn}^{2+}$ ions is retained. Indeed, $\mathrm{Sr}^{2+}$ ions were previously reported as able to create HAs with general 
TABLE 1 | ICP analysis showing the effective incorporation of doping ions in the as-synthesized apatite powders.

\begin{tabular}{|c|c|c|c|c|c|c|}
\hline Sample & $\begin{array}{l}\text { Initial } \mathrm{X}_{M g} \\
\text { (mol\%) }\end{array}$ & $\begin{array}{c}\text { Actual } X_{M g} \\
\text { (mol\%) }\end{array}$ & $\begin{array}{c}\text { Initial } \mathbf{X}_{S r} \\
\text { (mol\%) }\end{array}$ & $\begin{array}{c}\text { Actual } \mathbf{X}_{S r} \\
\text { (mol\%) }\end{array}$ & $\begin{array}{c}\text { Initial } X_{Z n} \\
\text { (mol\%) }\end{array}$ & $\begin{array}{c}\text { Actual } X_{Z n} \\
(\mathrm{~mol} \%)\end{array}$ \\
\hline $\mathrm{HA}$ & - & - & - & - & - & - \\
\hline $\mathrm{MgHA}$ & 15.0 & 6.1 & - & - & - & - \\
\hline MgSrHA & 15.0 & 6.2 & 1.5 & 1.47 & - & - \\
\hline MgZnHA & 15.0 & 5.8 & - & - & 5.0 & 4.9 \\
\hline
\end{tabular}

TABLE 2 | Crystal data of the as-obtained hydroxyapatite powders.

\begin{tabular}{lcccc}
\hline Sample & $\mathbf{a}(\mathbf{\AA})$ & $\mathbf{c}(\mathbf{\AA})$ & Cell vol. $\left(\AA^{\mathbf{3}}\right)$ & $\mathbf{D}_{a v}(\mathbf{n m})$ \\
\hline HA & 9.432 & 6.893 & 531.15 & 16.7 \\
MgHA & 9.438 & 6.888 & 531.45 & 19.7 \\
MgSrHA & 9.441 & 6.893 & 532.03 & 19.2 \\
MgZnHA & 9.434 & 6.886 & 530.74 & 15.9 \\
\hline
\end{tabular}

composition $\mathrm{Ca}, \mathrm{Sr}\left(\mathrm{PO}_{4}\right)_{6}(\mathrm{OH})_{2}$ without any solubility limit, but they are also known for ability to be incorporated in the $\beta$ TCP phase (Bigi et al., 1997; Kannan et al., 2006), and this explains the much higher extent of secondary phase found in S-MgSrHA sample (Table 4). Conversely, the formation of secondary phases occurs in much lower extent in the S-MgZnHA sample. This suggests that $\mathrm{Zn}^{2+}$ ions are largely retained in the structure of the HA phase, that is, as $\mathrm{Zn}$-doped HA, even after hightemperature sintering.

In the as-obtained HA/ $\beta$ TCP composites, the $\beta$ TCP phase can host $\mathrm{Mg}^{2+}, \mathrm{Sr}^{2+}$, and $\mathrm{Zn}^{2+}$ ions in partial substitution of $\mathrm{Ca}^{2+}$. This is confirmed also by the crystal analysis of the $\beta$ TCP phase, reporting that the cell parameters, particularly the cell volume, depart from typical values reported in literature toward the values of the whitlockite phase (a Mg-doped $\beta$ TCP phase) (Schroeder et al., 1977). In the sintered materials, the $\beta$ TCP phase shows reduced crystal growth, particularly in the multi-doped S-MgSrHA and S-MgZnHA (see $D_{a v}$ of $\beta$ TCP in Table 4); here the partial substitution of $\mathrm{Ca}^{2+}$ with $\mathrm{Mg}^{2+}$ and $\mathrm{Sr}^{2+} / \mathrm{Zn}^{2+}$ ions in the $\beta$ TCP lattice could have hampered the crystal growth.

\section{Morphological and Mechanical Characterization}

Gentle chemical etching of polished surfaces of the sintered bodies put in evidence the microstructure and grain morphology (Figure 4). Microscopic observation by SEM reveals that the same etching process carried out on the different materials resulted in a more pronounced corrosion effect in the multidoped ceramics, thus suggesting that the ion doping yielded a reduced chemical stability, thus enhanced biodegradability, in the sintered composites. The analysis of the SEM images reveals that S-HA sample shows some inhomogeneities in the microstructure, reported by large (i.e., $>2 \mu \mathrm{m}$ ) grains intercalated with much smaller ones. The average grain size for the four materials is: $\mathrm{S}-\mathrm{HA}=1.33 \pm 0.08 \mu \mathrm{m} ; \mathrm{S}-\mathrm{MgHA}=0.99 \pm 0.05 \mu \mathrm{m}$; $\mathrm{S}-\mathrm{MgSrHA}=0.88 \pm 0.04 \mu \mathrm{m} ; \mathrm{S}-\mathrm{MgZnHA}=0.95 \pm 0.06 \mu \mathrm{m}$. We thus found a much smaller (about $30 \%$ ) average grain size in the doped materials - particularly for S-MgSrHA- compared with the undoped S-HA.

We can observe that the smaller grain size detected in the multi-doped sintered materials is consistent with the reduced crystal size of their constituting HA and $\beta$ TCP phases (Table 4). This finding suggests that the microstructure of sintered HA/ $\beta$ TCP composites can be somewhat tailored by specific ions doping in the HA powders used as raw materials.

All the studied materials exhibit compression and flexural strengths in the range of the cortical bone (Keaveny and Hayes, 1993). The multi-doped samples (i.e., S-MgSrHA, S-MgZnHA) result in less resistance to compression in respect to the undoped $\mathrm{S}-\mathrm{HA}$ and the single doped S-MgHA (Figure 5A). Conversely, doped and multi-doped materials show higher flexural strength than the undoped S-HA; particularly, S-MgSrHA exhibits the highest flexural strength (Figure 5B). The much lower flexural strength of S-HA can be related to microstructural inhomogeneities that act as critical defects under loading. On the other hand, the much smaller grain size, particularly of $\mathrm{S}-\mathrm{MgSrHA}$, can have promoted enhanced fracture strength under flexure. Conversely, multi-doped materials show the lowest compressive strength, in comparison with the undoped S-HA and the single-doped S-MgHA.

Nanoindentation tests reveal no significant differences between the hardness values of the tested sintered bodies (Figure 6A). However, doped and multi-doped materials show a slight increase in the hardness mean value. As well, the values of Young's modulus in the multi-doped materials (with a slight prevalence for S-MgSrHA) are about $8 \%$ greater compared with $\mathrm{S}-\mathrm{HA}$ and S-MgHA (Figure 6B). Noticeably, the data dispersion is much lower in the multi-doped materials that confirm the structural inhomogeneity detected in S-HA by microscopic observations (Figure 4).

The greater flexural strength and higher value of hardness and Young's modulus found in ion-doped sintered materials can be ascribed to the reduced grain size according to a HallPetch-like law-which could also be interpreted as a reduced size of critical flaws responsible of the ceramic fracturing-by virtue of the Griffith law $\left(\sigma K_{C} / c^{1 / 2}\right)$, where $\sigma$ is the strength, $K_{c}$ is the fracture toughness, and $c$ is the size of the critical defect (Griffith, 1921) (in Hall-Petch law $c$ is the grain size thus assumed in Griffith law as proportional to the flaw size). However, note that the exponents observed in our experiments are different from the 0.5 theoretical value and for flexural strength, hardness, and Young's modulus are, respectively, 1.7, thus showing a very efficient strengthening mechanisms, 0.2 , and again 0.2 . 

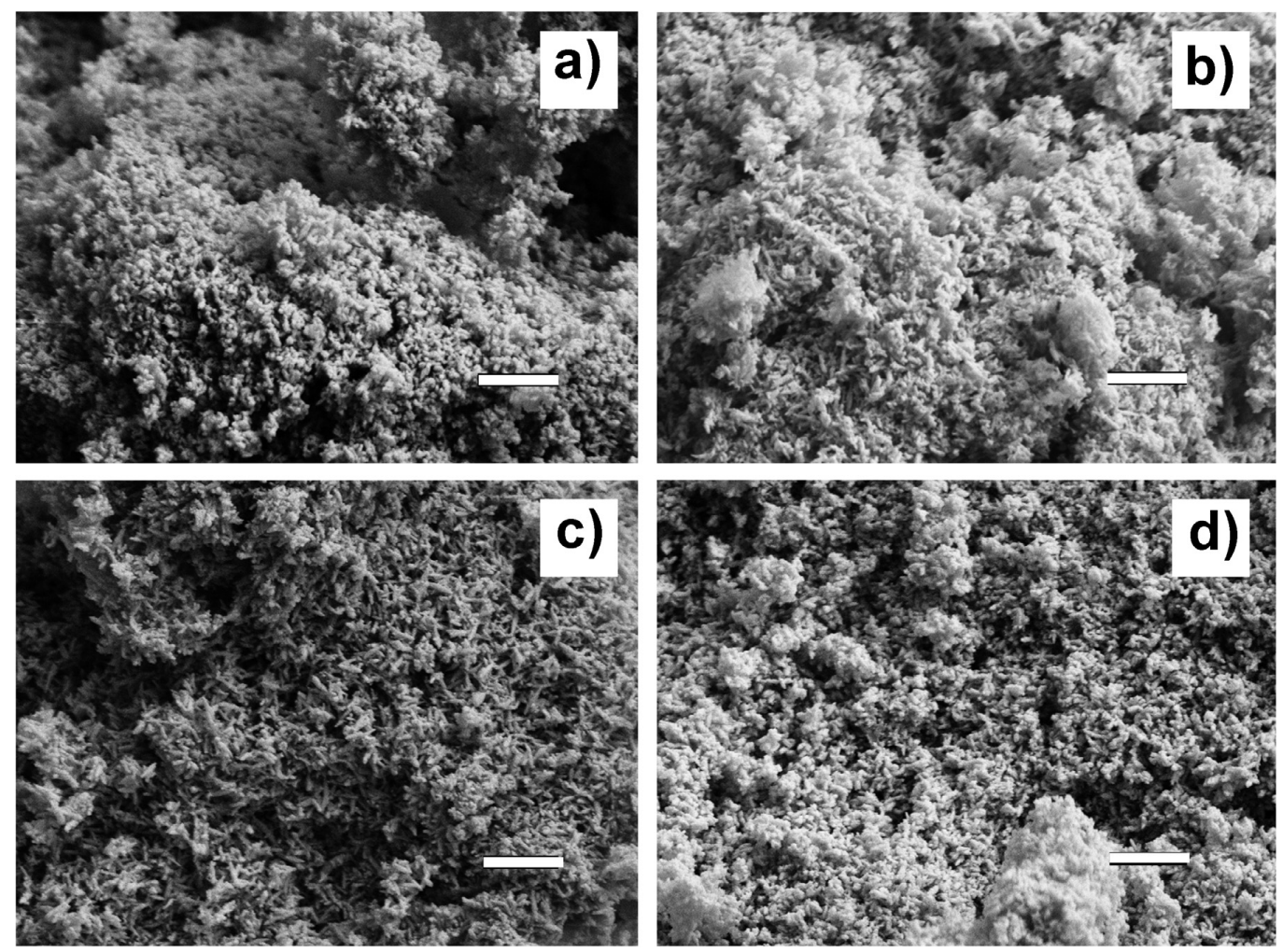

FIGURE 2 | SEM micrographs of the as-synthesized apatite powders. (a) HA; (b) MgHA; (c) MgSrHA; and (d) MgZnHA. Scale bar: 500 nm.

Accordingly, we can hypothesize that the degradation of the HA phase into BTCP occurring in our doped materials upon sintering resulted in the formation of new crystals at the grain boundaries of HA phase, thus creating a condition of pre-stress further-in addition to grain size reduction-preventing crack propagation and enhancing the flexural strength (as well as hardness and Young's modulus).

\section{Analysis of the lons Release Profile}

The release of ions from the sintered bodies is investigated to obtain the solubility profile in physiological environment (Hanks' Balanced Salt solution). We show the release profile of $\mathrm{Ca}^{2+}, \mathrm{Mg}^{2+}$, and $\mathrm{Zn}^{2+}$ ions, expressed in absolute values (Figure 7) and as a percentage of the initial ion content in the material (Figure 8). The undoped S-HA shows the lowest extent of $\mathrm{Ca}^{2+}$ and $\mathrm{Mg}^{2+}$ ion release, whereas S-MgZnHA shows the highest one. No detectable release of $\mathrm{Sr}^{2+}$ ions is observed along the whole experiment; conversely, $\mathrm{Mg}^{2+}$ ions are released in large extent over time, whereas $\mathrm{Zn}^{2+}$ release is detected in much lesser extent than $\mathrm{Mg}^{2+}$ and $\mathrm{Ca}^{2+}$ (see particularly Figure 8). The ions release profile can be described by two distinct mechanisms. In fact, the first 3 days are characterized by fast ion release, while in the subsequent stage the release kinetic was slower. This suggests that, within the first stage, the release process involves ions characterized by relatively weaker bonds; we hypothesize that such ions are located in surface regions characterized by reduced binding energy in respect to the bulk. In the subsequent stage (i.e., days 3-14), the release of $\mathrm{Ca}^{2+}, \mathrm{Mg}^{2+}$, and $\mathrm{Zn}^{2+}$ ions is slackened, particularly $\mathrm{Zn}^{2+}$ release stops at the day 3 . Considering that the HA phase is characterized by low solubility at physiological $\mathrm{pH}$, in respect to $\beta$ TCP, we can hypothesize that the released ions are prevalently dissolution products of $\beta$ TCP phase. Taking into account that no $\mathrm{Sr}^{2+}$ ions release is detected, we can speculate that $\mathrm{Sr}^{2+}$ ions are entirely located in energetically stable substitutional lattice positions of HA and/or $\beta$ TCP phase. Similarly, the halt of the $\mathrm{Zn}^{2+}$ ion release after 7 days suggests that only a small fraction of these ions is located into crystal sites characterized by low binding energy. Indeed, the high electronegativity of zinc, in comparison with calcium and strontium (i.e., $\mathrm{Zn}=1.6$; $\mathrm{Sr}=\mathrm{Ca}=1.0$ ), supports the hypothesis that $\mathrm{Zn}^{2+}$ ions are stably incorporated into the HA lattice as a $\mathrm{Zn}$-doped HA, thus limiting its segregation into the secondary $\beta$ TCP phase. Hence, the very low extent of $\mathrm{Zn}$ release can be ascribed to the small fraction of $\mathrm{Zn}^{2+}$ ions incorporated, together with $\mathrm{Mg}^{2+}$, in the $\beta$ TCP structure, which is characterized by higher solubility at physiological $\mathrm{pH}$.

\section{Gene Expression of Human Extracellular Matrix and Adhesion Molecules}

Gene expression profiles of human ECM and adhesion molecules were evaluated by array technology. To this purpose, hASCs were grown on the sintered apatites and on TCPS, as control, until day 14 . 


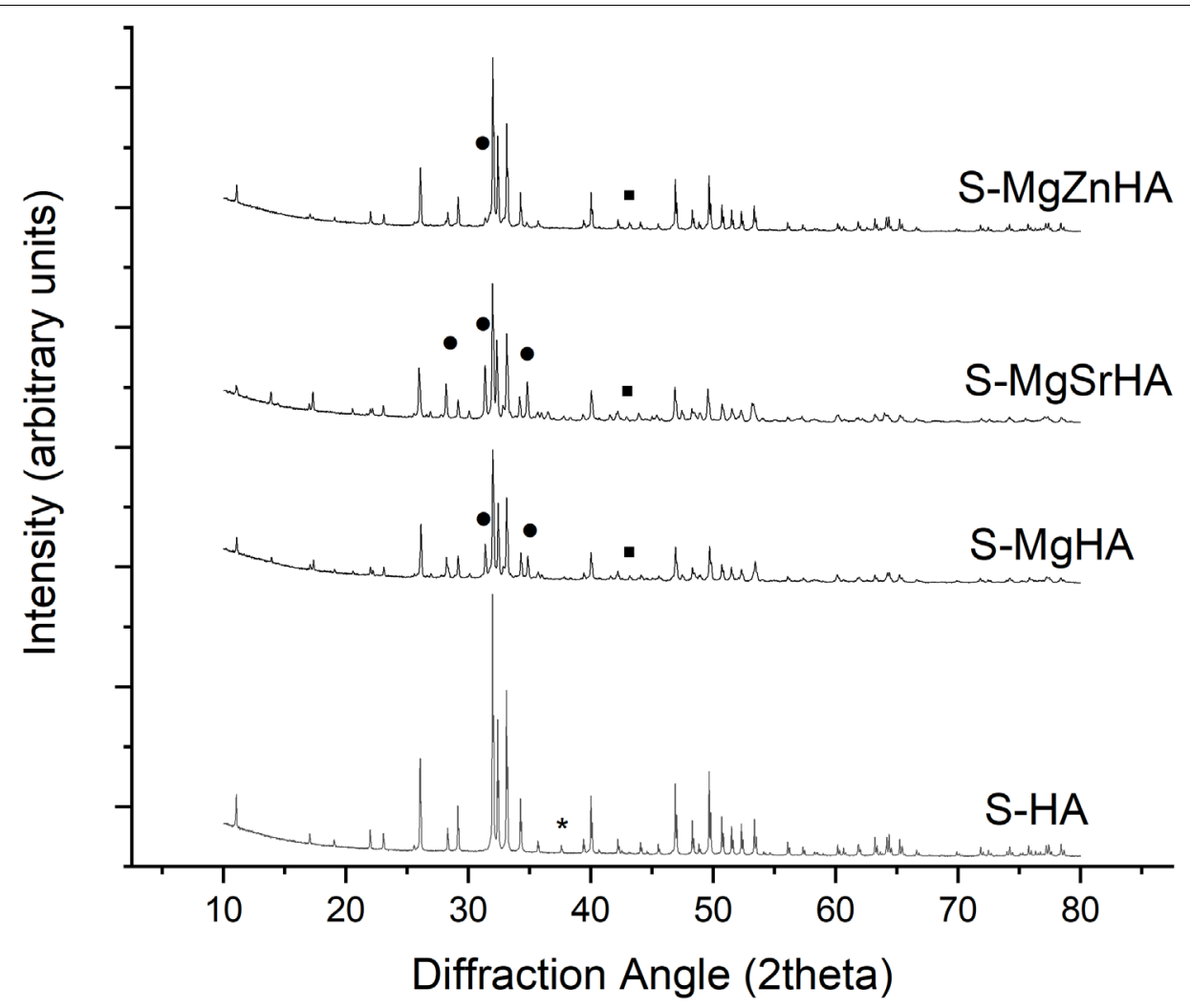

FIGURE 3 XRD spectra of the sintered apatites. The symbols highlight relevant peaks of the secondary phases. ${ }^{*}=\mathrm{CaO} ; \boldsymbol{*}^{*}=\mathrm{MgO} ;{ }^{\bullet}=\beta \mathrm{TCP}$. All the remaining reflections belong to hydroxyapatite phase. Miller indices related to the most intense XRD reflections of the various crystalline phases are reported.

TABLE 3 | Ca/P molar ratio and doping ions content in the sintered materials, as obtained by ICP analysis.

\begin{tabular}{lcccc}
\hline Sample & Molar Ca/P & $\mathbf{X}_{\boldsymbol{M g}}$ (mol\%) & $\mathbf{X}_{\mathbf{S r}}$ (mol\%) & $\mathbf{X}_{\mathbf{Z n}}$ (mol\%) \\
\hline S-HA & 1.70 & - & - & - \\
S-MgHA & 1.57 & 5.2 & - & - \\
S-MgSrHA & 1.56 & 5.5 & 1.3 & - \\
S-MgZnHA & 1.53 & 4.1 & - & 5.0 \\
\hline
\end{tabular}

A total of 33 differentially expressed genes (DEG) including 31 upregulated genes (red) and 2 downregulated genes (green) are identified in the hASC grown on S-HA material (Figure 9A). Specifically, the DEG positively modulated from S-HA material encoding for integrin proteins, such as Integrin alpha-2,3,5,6 (ITGA-2,3,5,6) and Integrin beta 5 (ITGB5). ECM proteins, such as nine collagen proteins called Collagen, type I, alpha 1; Collagen, type IV, alpha 2; Collagen, type V, alpha 1; Collagen, type VI, alpha 1,2; Collagen, type VII alpha 1; Collagen, type XII, alpha 1; Collagen, type XIV, alpha 1; Collagen, type XVI, alpha 1 (COL1A1, COL4A2, COL5A1, A2, COL6A1, COL7A1, COL12A1, COL14A, COL16A1), are detected as upregulated on hASCs grown on S-HA material. Five matrix metalloproteinases (MMPs) are upregulated by S-HA material (MMP1,2,3,14,16). PCR data demonstrated that S-HA material induces in hASCs upregulation of a specific gene involved in bone mineralization and ossification, such as secreted phosphoprotein 1 (SPP1). Versican (VCAN) and Integrin beta 1 (ITGB1) expression genes are downregulated in hASC grown on S-HA.

A total of 40 DEGs, including 38 upregulated genes and 2 downregulated genes, are identified in hASC cultures grown on S-MgHA material (Figure 9B). Specifically, the DEG modulated from S-MgHA genes encoding for four integrin proteins, named integrin alpha-5, 6 (ITGA- 5,6), and Integrin beta 3, beta 5 $(I T G B 3,5)$. ECM proteins, such as nine collagen proteins, as a COL1A1, COL4A2, COL5A1 COL6A1-A2 COL11A1, COL12A1, COL14A1, COL16A1, are upregulated on hASCs grown on $\mathrm{S}-\mathrm{MgHA}$ material. The expression of five MMPs genes are upregulated by S-MgHA material, as a MMP1, 2, 3, 14, 16. Data obtained by array technology demonstrate that S-MgHA biomaterial induces in hASCs an upregulation of osteoblastrelated gene such as secreted protein acidic and rich in cysteine (SPARC). SPARC codified for osteonectin protein that is one of the most abundant non-collagenous protein expressed in mineralized tissues. Versican (VCAN) gene was downregulated in hASCs grown on S-MgHA.

A total of 17 DEGs, including 11 upregulated genes and 6 downregulated genes, are identified in the hASCs at day 14 grown on S-MgSrHA material (Figure 9C). The DEG modulated from S-MgSrHA genes encode four integrins, such as ITGA$2,3,5,6$, compared to the control (TCPS). The S-MgSrHA material behaves in a manner similar to S-HA, that is, positively modulates 
TABLE 4 | Crystal data on the HA and TCP phases composing the sintered ceramics.

\begin{tabular}{|c|c|c|c|c|c|c|c|c|c|}
\hline Sample & $\begin{array}{l}\text { a (Å) } \\
\text { (HA) }\end{array}$ & $\begin{array}{l}\text { c (Å) } \\
(\mathrm{HA})\end{array}$ & $\begin{array}{l}\text { Cell vol. }\left(\AA^{3}\right) \\
\text { (HA) }\end{array}$ & $\begin{array}{c}\mathrm{D}_{a v}(\mathrm{~nm}) \\
(\mathrm{HA})\end{array}$ & $\begin{array}{c}\% \beta \text { TCP } \\
\text { phase }\end{array}$ & $\begin{array}{c}a(\AA) \\
(\beta \text { TCP })\end{array}$ & $\begin{array}{c}c(\AA) \\
(\beta \text { TCP) }\end{array}$ & $\begin{array}{c}\text { Cell vol. }\left(\AA^{3}\right) \\
(\beta \text { TCP })\end{array}$ & $\begin{array}{c}\mathrm{D}_{a v}(\mathrm{~nm}) \\
(\beta \text { TCP) }\end{array}$ \\
\hline $\mathrm{S}-\mathrm{HA}$ & 9.420 & 6.886 & 529.79 & $444 \pm 6$ & - & - & - & - & - \\
\hline S-MgHA & 9.428 & 6.883 & 529.84 & $163 \pm 2$ & 20 & 10.363 & 37.355 & 3474.0 & $149 \pm 6$ \\
\hline S-MgSrHA & 9.413 & 6.910 & 530.23 & $139 \pm 2$ & 36 & 10.363 & 37.316 & 3470.3 & $126 \pm 3$ \\
\hline S-MgZnHA & 9.425 & 6.894 & 530.39 & $225 \pm 3$ & 9 & 10.385 & 37.315 & 3485.3 & $130 \pm 5$ \\
\hline
\end{tabular}

TABLE 5 | pH values of all samples incubated for $24 \mathrm{~h}$ at $37^{\circ} \mathrm{C}$ either in physiologic solution or in Luria Bertani culture medium.

\begin{tabular}{|c|c|c|}
\hline & \multicolumn{2}{|c|}{$\mathrm{pH}$} \\
\hline & Physiologic solution & Luria Bertani broth \\
\hline $\mathrm{S}-\mathrm{HA}$ & 7 & 7 \\
\hline S-MgHA & 7 & 7 \\
\hline S-MgSrHA & 9 & 9 \\
\hline S-MgZnHA & 7 & 7 \\
\hline
\end{tabular}

the expression of the osteogenic gene SPP1. Downregulated genes in hASCs grown on S-MgSrHA were CD44 molecule (CD44), ADAM metallopeptidase with thrombospondin type 1 motif, 1 (ADAMTS1), Transforming growth factor, beta-induced (TGFBI), contactin-1 (CNTN1), COL16A1, and ITGB5.

A total of 30 DEG, including 27 upregulated genes and 3 downregulated genes, are identified in the hASCs grown on S-MgZnHA material (Figure 9D). Specifically, the DEG modulated from S-MgZnHA genes encoding for four integrins, specifically ITGA- 1,5,6 and Integrin beta 3 (ITGB 3), are positively modulated by $\mathrm{S}-\mathrm{MgZnHA}$ compared to the control TCPS. ECM proteins, such as the five collagen proteins COL6A1, COL11A1, COL14A1, COL16A1, COL4A2, are detected upregulated on hASCs grown on S-MgZnHA material. The expression of 5 MMPs genes (MMP 1,2,3, 14, 16) are upregulated. Downregulated genes in hASCs grown on S-MgZnHA are the Versican (VCAN) Integrin beta 1 (ITGB1) and CD44 molecule (CD44). All materials upregulate the Fibronectin 1(FN1) gene expression and Thrombospondin 3 (THBS3).

\section{Microbiological Analyses}

The antimicrobial tests on the sintered materials were performed through the MTT colorimetric assay. The viability of both bacterial strains was investigated on (1) both the planktonic bacterial cultures after their removal from the sintered materials (Figure 10); and (2) directly onto the sintered materials after $24 \mathrm{~h}$ bacterial incubation (Figure 11).

In Figure 10 viability data of both $E$. coli and $S$. aureus planktonic bacterial cultures after being in direct contact for $24 \mathrm{~h}$ and then removed from the sintered materials are reported. The comparison of cell viability between E. coli (Aa) and S. aureus (Ab) related to TCPs set as $100 \%$ showed some differences: S-MgZnHA (25\%) results as the most active material in reducing E. coli cell viability followed by S-MgSrHA (50\%), whereas $\mathrm{S}-\mathrm{MgHA}$ is less effective (76\%) (Figure 10Aa). For S. aureus, the percentage of cell viability is different: S-MgSrHA (76\%) and
S-MgHA (78\%) show similar values whereas S-MgZnHA (95\%) does not show any evident decrease (Figure 10Ab). The trend is quite similar if the viability data detected for both bacterial strains and all samples are reported to S-HA samples set as $100 \%$ (Figures 10Bc,d).

In Figure 11 is shown the percentage of viability of both bacterial strains adherent to the S-HA and to the iondoped sintered samples. The adhesion of both bacterial strains, considering TCP set as 100\% (Figure 11A), is quite reduced on $\mathrm{S}-\mathrm{MgSrHA}$ samples, in particular showing the best performance with S. aureus (10\%) (Figure 11Ab) in comparison to E. coli ( 20\%) (Figure 11Aa). The results on S-MgSrHA samples for both bacterial strains are better in respect to S-HA; the other two materials (S-MgHA and S-MgZnHA) show a reduced cell adhesion even if it was higher in comparison to S-MgSrHA, although more effective in $S$. aureus. The trend is similar if the percentage of adhesion detected for both bacterial strains and all samples are reported to S-HA set as $100 \%$ (Figures $\mathbf{1 1 B c}, \mathbf{d}$ ).

The adhesion data are further supported by CLSM images shown in Figure 12. Both bacterial strains were seeded and then incubated for $24 \mathrm{~h}$ on S-HA and the ion-doped sintered samples. After washing and staining, dead cells fluoresce red, while cells fluorescing green are deemed viable (see full method description in the Materials and Methods section). Figure 12 shows greenfluorescing viable cells in the control (S-HA) for both bacterial strains (Figures 12Aa,b,Bi,l). While with both bacterial cells cultured on S-MgSrHA almost widespread cellular death is observed (Figures 12Ae,f,Bo,p), a partial reduction of viable cells is detected for both strains when incubated onto S-MgZnHA (Figures 12Ag,h,Bq,r). The effect is less evident on S-MgHA (Figures 12Ac,d,Bm,n). In addition, on S-MgSrHA samples the dead cells are localized close to the surfaces. Interestingly, the $\mathrm{pH}$ value of S-MgSrHA samples (Table 5) incubated for $24 \mathrm{~h}$ at $37^{\circ} \mathrm{C}$ either in physiologic solution or in Luria Bertani culture medium was around 9, quite higher if compared to the others samples.

\section{DISCUSSION}

The results obtained in the present work show that when HA powders obtained by wet synthesis process are sintered, the doping of the apatitic crystals with multiple ions is able to induce the formation of HA/ $\beta$ TCP composites with enhanced mechanical and biologic ability. In particular, we found that, besides the formation of $\beta$ TCP as a secondary phase during the sintering process, the ion doping confines the crystal growth 


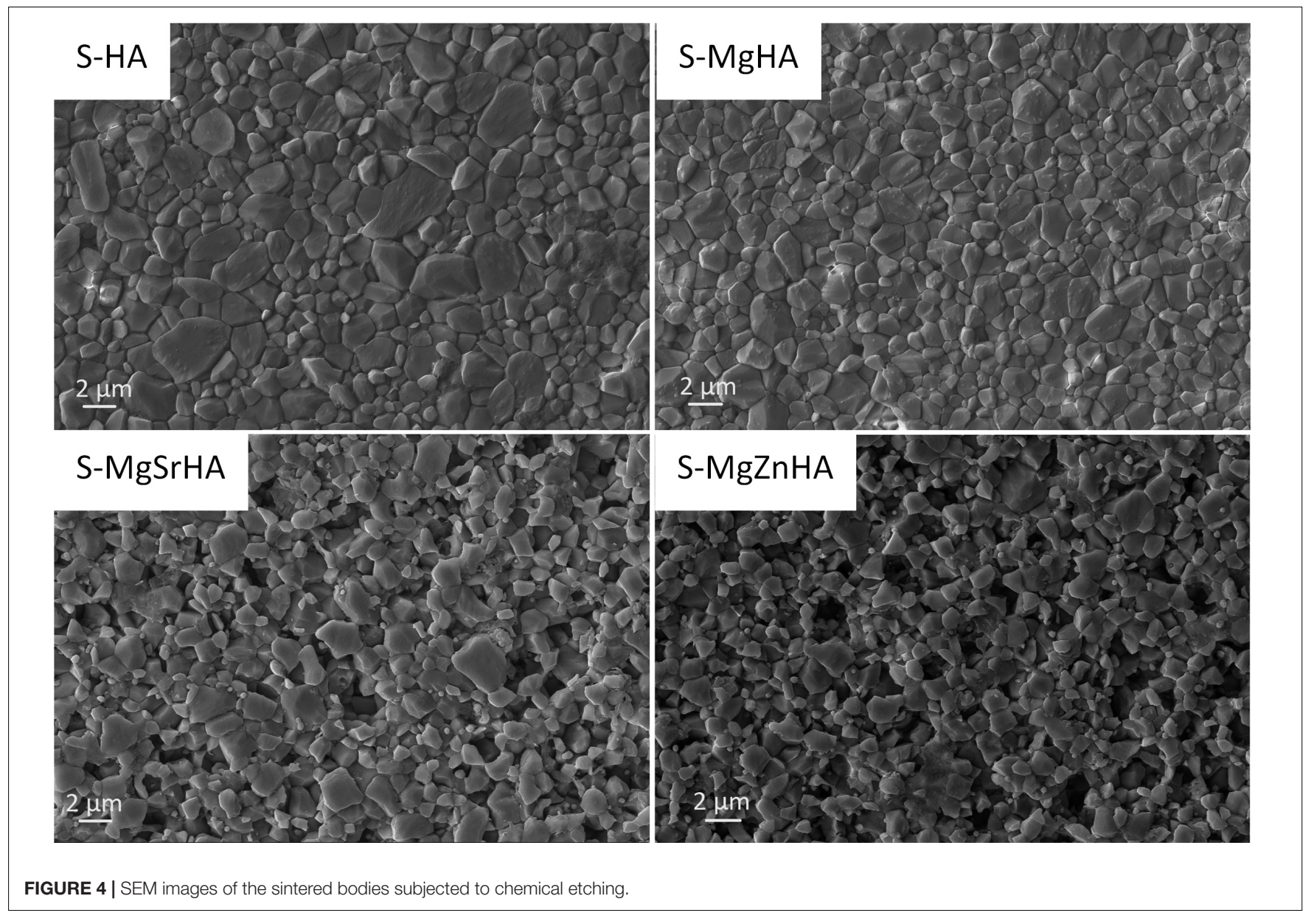

A

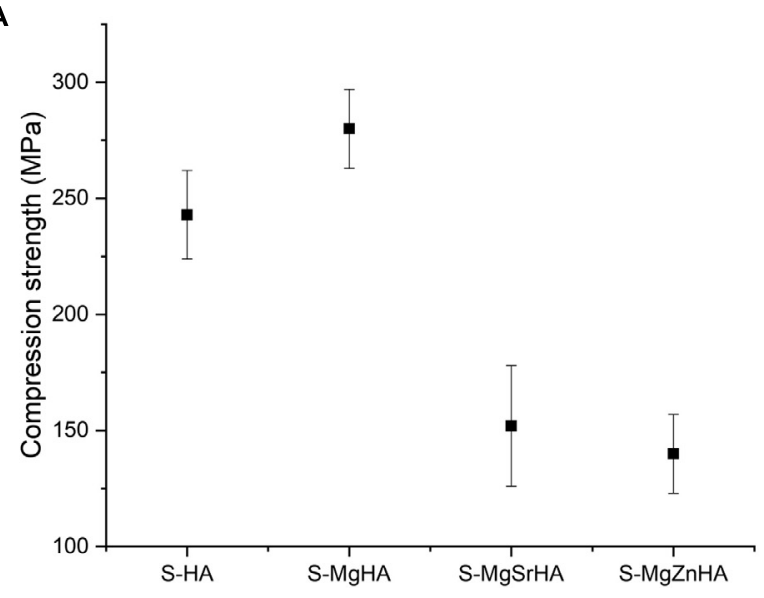

B

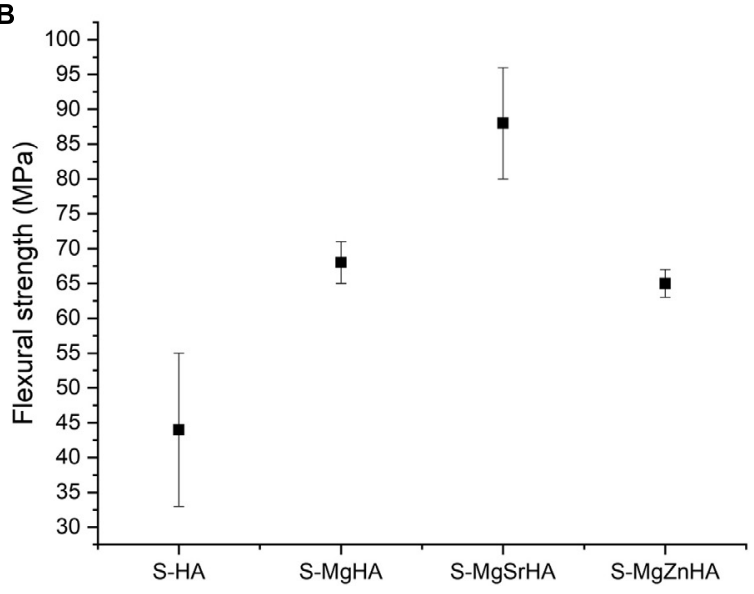

FIGURE 5 | Mechanical properties of sintered bodies. (A) Compressive strength and (B) flexural strength.

and induces microstructural changes in the final ceramics, particularly when the doping is realized with more than one type of ions. Generally, such modifications are found to be effective in enhancing the mechanical properties in the sintered materials, particularly the flexural strength, in comparison with S-HA.
Considering the Mg-doped HA phase, $\mathrm{Mg}^{2+}$ ions are unstable in substitutional lattice sites, likely due to its smaller size in comparison with $\mathrm{Ca}^{2+}$ ion; therefore, besides a partial substitution in the $\mathrm{Ca}^{2+}$ sites, they are supposed to occupy also the disordered hydrated surface layer typical of nanocrystalline 
A

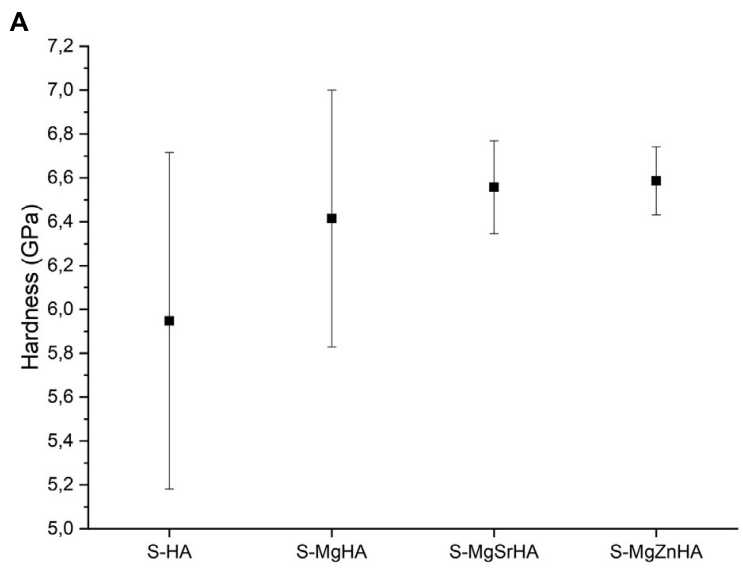

B

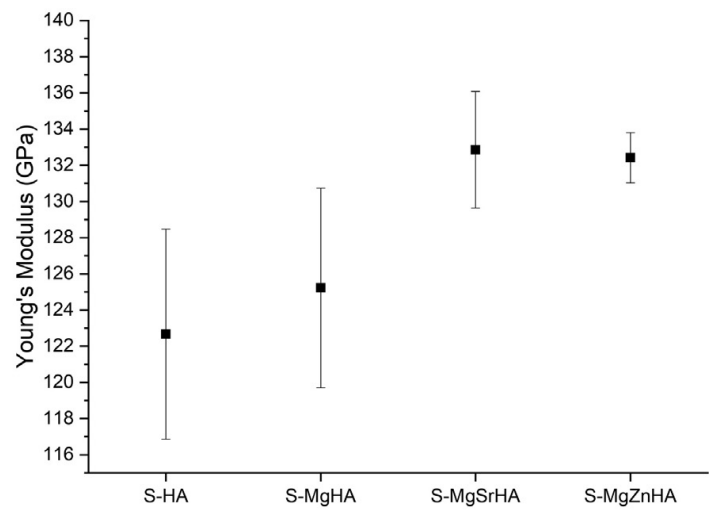

FIGURE 6 | Mechanical properties obtained by nanoindentation of sintered bodies. (A) Hardness and (B) Young's modulus.

A

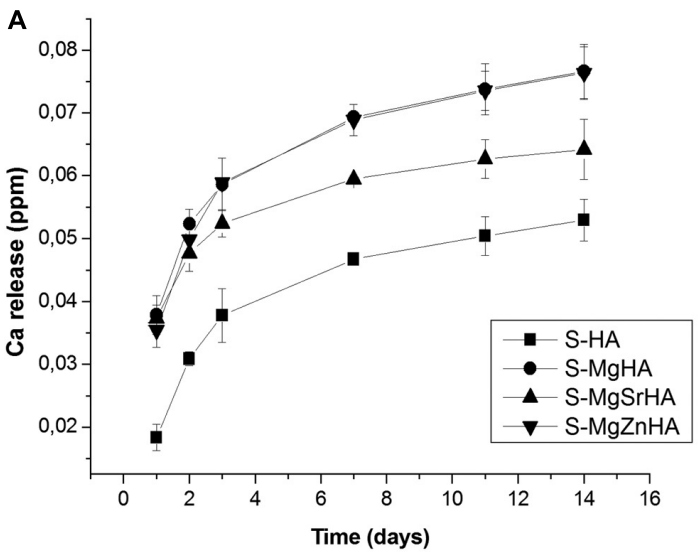

B

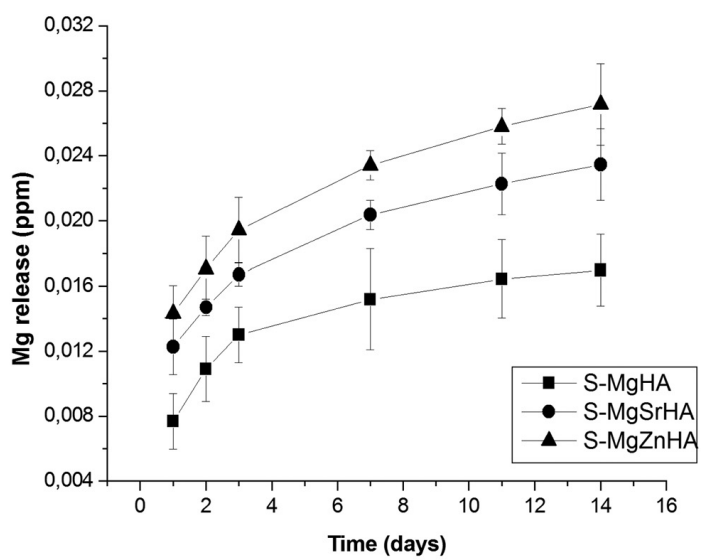

C

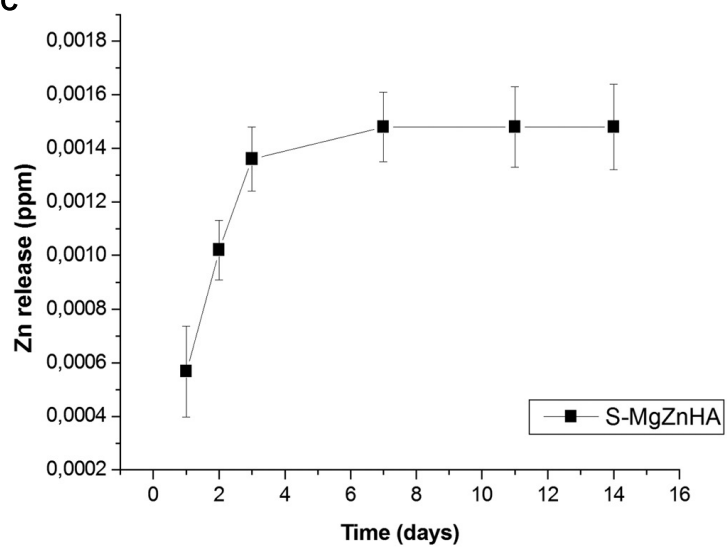

FIGURE 7 | lon release in physiological fluid: absolute values of released ions: (A) Ca release; (B) Mg release; and (C) Zn release.

apatites synthesized at near body temperature (Bertinetti et al., 2009). Thus, during sintering the HA phase tends to crystallize in stable lattice structures, whereas $\mathrm{Mg}^{2+}$ ions are segregated at the grain boundaries, inducing the formation of Mg- $\beta$ TCP phase (whitlockite) (Zima et al., 2011). This phenomenon is associated with a decrease of the grain size, in turn yielding a strong increase of the flexural strength in the S-MgHA material. In the case of multiple ions doping the scenario is more 

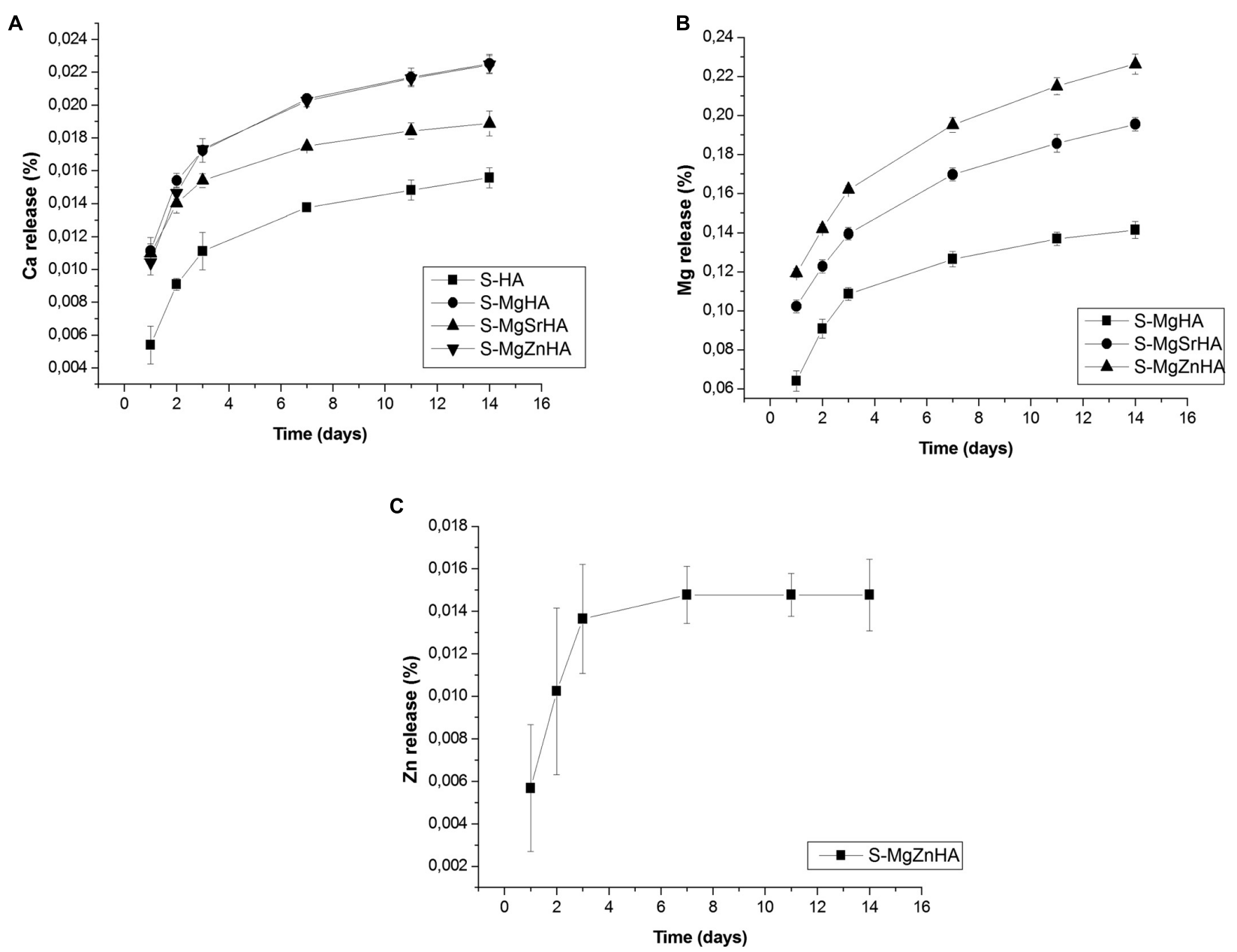

FIGURE 8 | lon release in physiological fluid: percentage values of released ions in respect to those present in the starting material: (A) Ca release; (B) Mg release; and (C) $\mathrm{Zn}$ release.

complicated, due to the occurrence of multiple interactions. Contrary to $\mathrm{Mg}^{2+}$, both $\mathrm{Sr}^{2+}$ and $\mathrm{Zn}^{2+}$ have previously shown good ability to substitute $\mathrm{Ca}^{2+}$ inside the HA lattice. Particularly, $\mathrm{Sr}^{2+}$ can be extensively retained even after sintering, but it is also a promoter of $\beta$ TCP phase formation (Boanini et al., 2019), as confirmed by our data reporting the formation of $36 \mathrm{wt} \%$ of $\beta$ TCP in the S-MgSrHA material. On the other hand, the co-doping with $\mathrm{Mg}^{2+}$ and $\mathrm{Sr}^{2+}$ ions results as the most effective to achieve grain size reduction, thus resulting in the highest flexural strength among the studied materials, doubling the values recorded with S-HA. Differently, in the case of S-MgZnHA the co-doping with $\mathrm{Mg}^{2+}$ and $\mathrm{Zn}^{2+}$ yields limited formation of $\beta$ TCP phase $(9 \mathrm{wt} \%)$. $\beta$ TCP can be partially substituted with $\mathrm{Zn}^{2+}$, in agreement with Boanini et al. (2019) reporting a certain solubility of $\mathrm{Zn}^{2+}$ in the $\beta$ TCP phase (max 10\%at). As for $\mathrm{Sr}^{2+}$, also the doping with $\mathrm{Zn}^{2+}$ ions is effective in reducing the grain size of the sintered S-MgZnHA material, and thus greatly increasing the flexural strength, in respect to S-HA. All these results indicate that ion doping can be designed to induce structural disorder in sintered CaPs, that we found to be greatly beneficial for the mechanical performance.

In a different perspective, the changes in the phase composition of the sintered materials, as induced by ion doping, are correlated to enhanced ion exchange ability along 14 days of soaking into a physiological-like medium at body temperature. Particularly, S-MgZnHA shows the highest release of $\mathrm{Ca}^{2+}$ and $\mathrm{Mg}^{2+}$ ions, but a very low release of $\mathrm{Zn}^{2+}$. This confirms recent results obtained with as-synthesized multi-doped ( $\mathrm{Mg}, \mathrm{Zn})$-HA powders (Boanini et al., 2019), reporting no $\mathrm{Zn}$ release, thus suggesting a high stability of $\mathrm{Zn}^{2+}$ ions in the HA lattice. Due to the low extent of $\mathrm{Zn}$ release, our results suggest that $\mathrm{Zn}^{2+}$ ions retain good stability in the HA lattice even after sintering.

The enhanced physicochemical properties found in ion-doped sintered CaPs can be directly related to the good osteogenicrelated gene expression and enhanced resistance to biofilm formation, as shown by the cell tests carried out with hASC and with two different Gram+ and Gram- bacterial strains, frequent in post-surgical infections: S. aureus and E. coli. In the present study, we found that all the sintered materials 


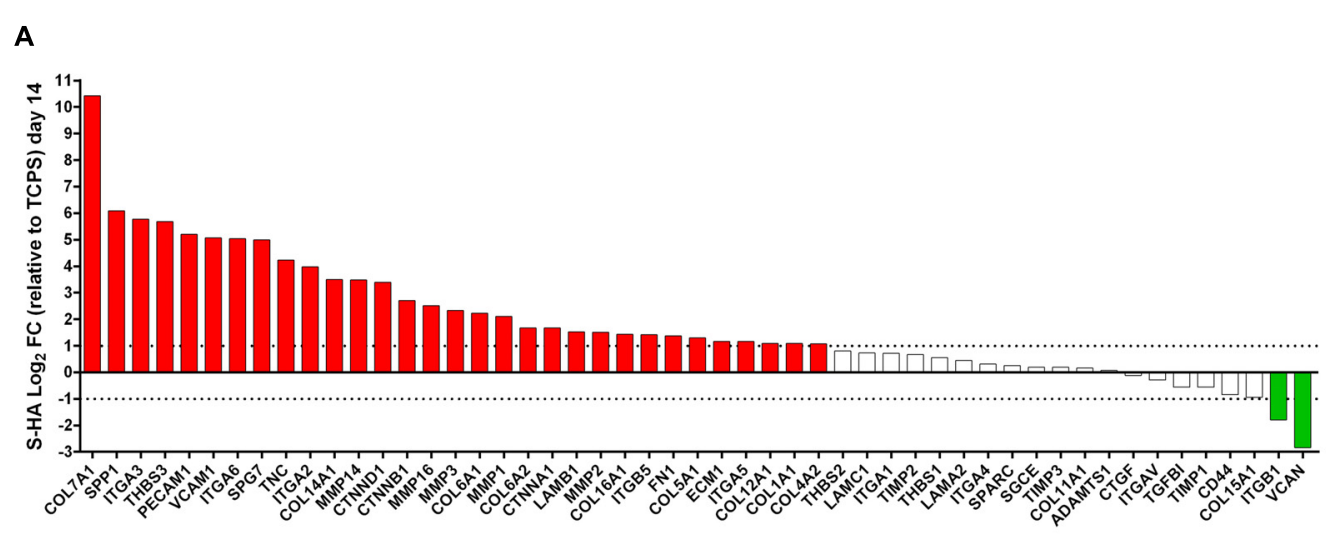

B

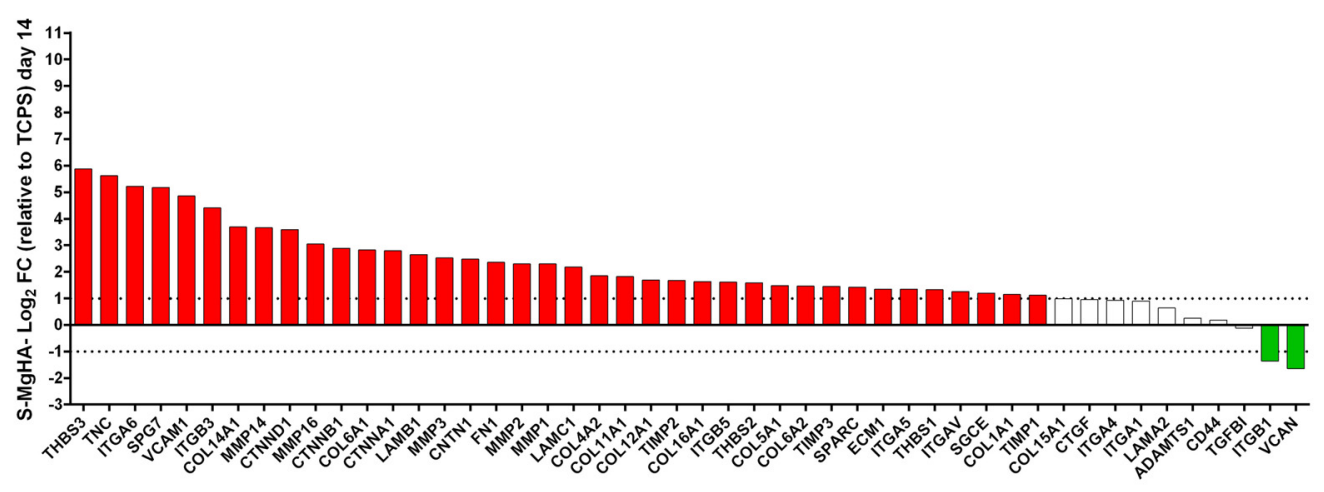

C

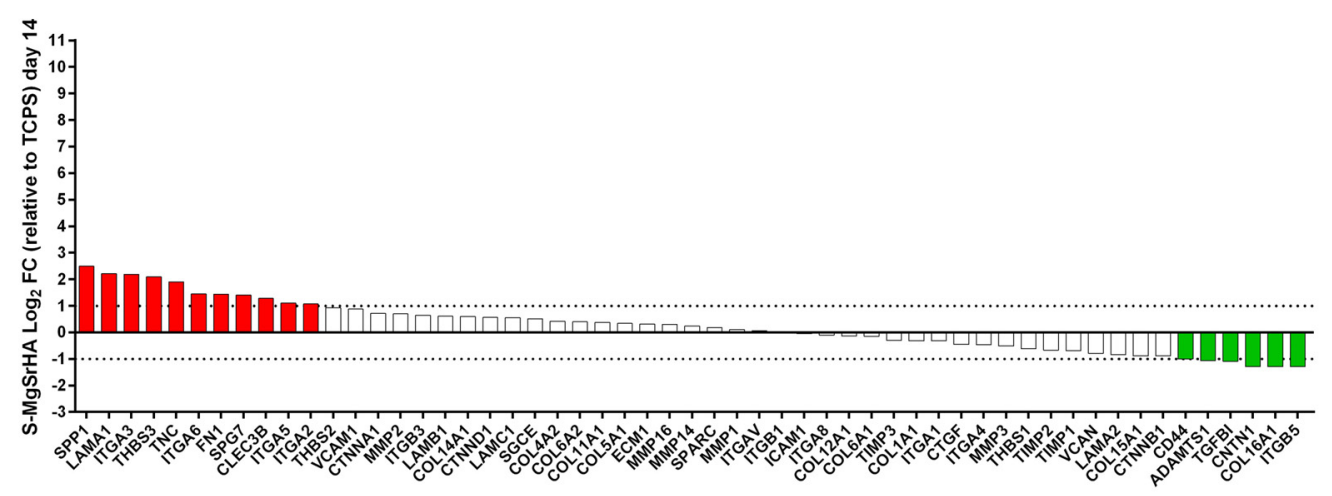

D

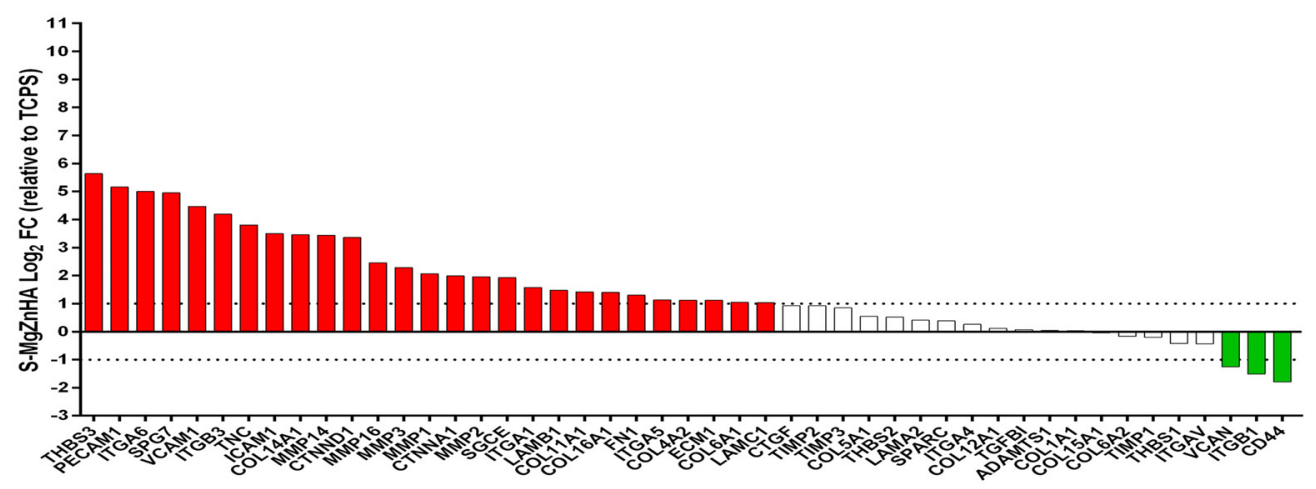

FIGURE 9 | Differentially Expressed Genes (DEG) from the sintered apatites. (A) S-HA; (B) S-MgHA; (C) S-MgSrHA; and (D) S-MgZnHA. 


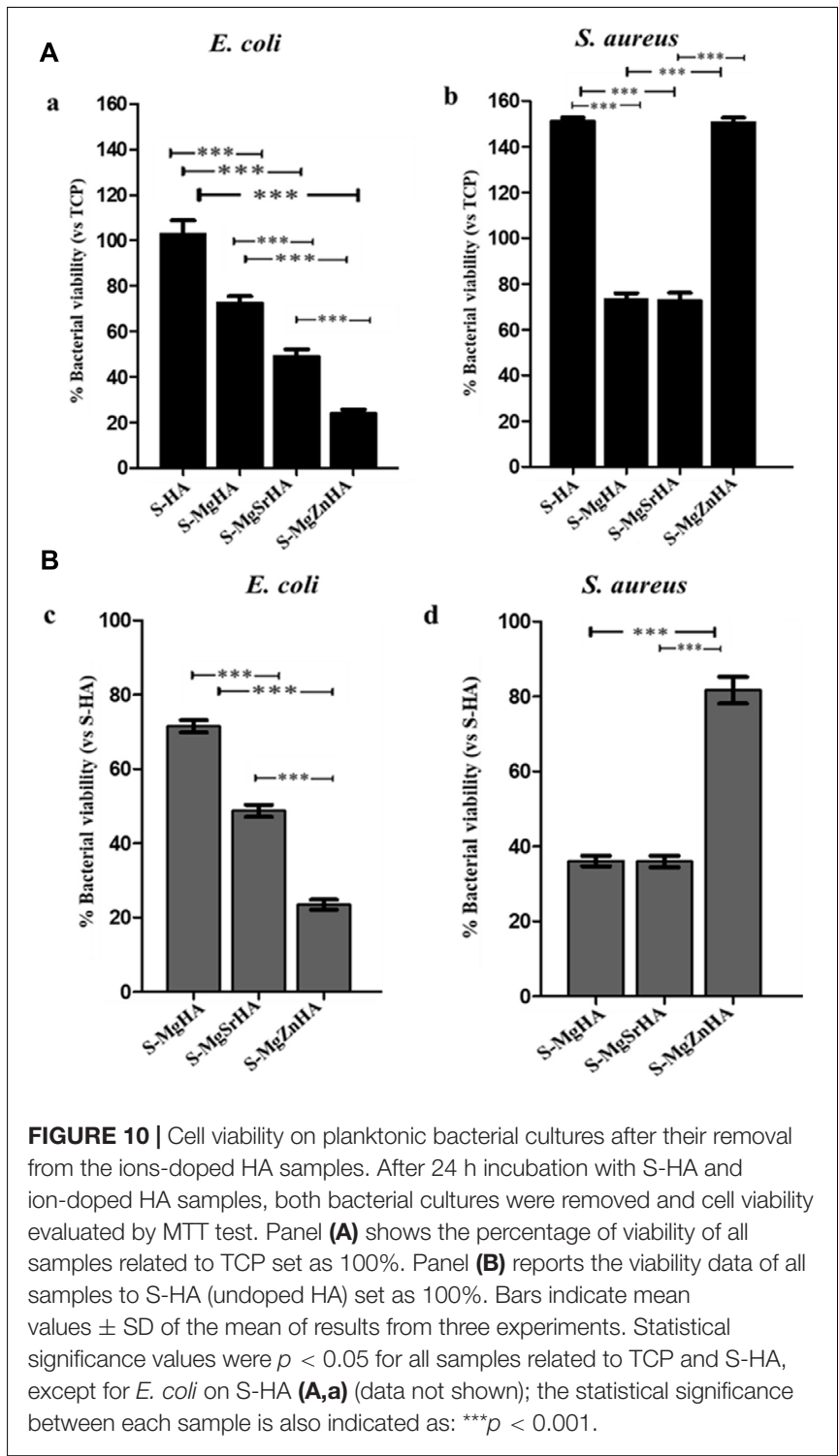

here studied show upmodulation of genes encoding ECM, various adhesion molecules (integrins) and, also, of the gene Thbs3, this latter codifying the Thrombospondin 3 protein, a polypeptide structurally similar to the cartilage oligomeric matrix protein (COMP/TSP5), that mediate cell-to-cell and cellto-matrix interactions. This finding reports good ability of the sintered CaPs to promote cell adhesion and proliferation, as well as favoring new bone tissue formation and osteointegration (Dalby et al., 2014; Docheva et al., 2014). The genes encoding for collagen proteins and MMP, relevant for the regulation of bone tissue maturation and sensitive to nanoscale surface features (Hankenson et al., 2005; von der Mark et al., 2010; Paiva and Granjeiro, 2017), are as well upregulated by all the studied material, with the exception of S-MgSrHA samples. Previous works reported that Sr-doped HA nanoparticles, microcapsules, bioglasses, and bone cements were effective in enhancing collagen type I expression and formation (Capuccini et al., 2009;

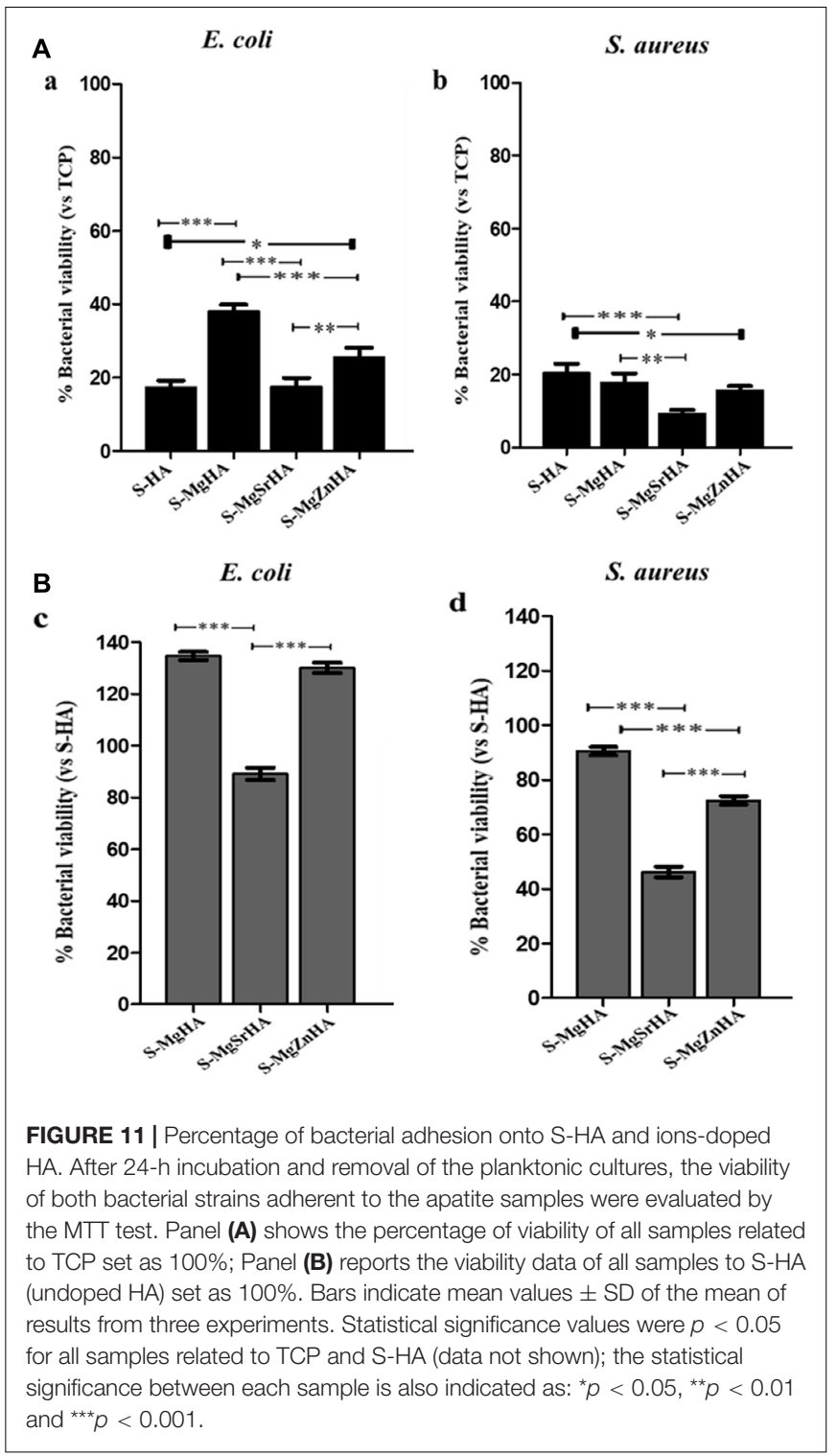

Huang et al., 2016; Khan et al., 2016; Henriques Lourenço et al., 2017; Montesi et al., 2017), whereas no studies reported on the effect of strontium on MMP expression. However, these previous results were obtained with nanostructured and nanocrystalline materials, synthesized at near body temperature and characterized by high surface activity and greater ability of releasing $\mathrm{Ca}^{2+}, \mathrm{PO}_{4}{ }^{3-}$, and $\mathrm{Sr}^{2+}$ ions, in comparison with sintered ceramics. In our case, $\mathrm{S}-\mathrm{MgSrHA}$ did not release any $\mathrm{Sr}^{2+}$ ions along 14 days, thus suggesting high stabilization of this ion in the structure of both HA and $\beta$ TCP phases that could have affected the expression of collagen-related genes at day 14 . To be noted that this study does not consider gene expression in shorter (or longer) follow-up times; therefore, we are unable to say whether collagen-related genes may be upregulated by S-MgSrHA at different times. However, S-MgSrHA shows overexpression of osteogenic genes such 
A

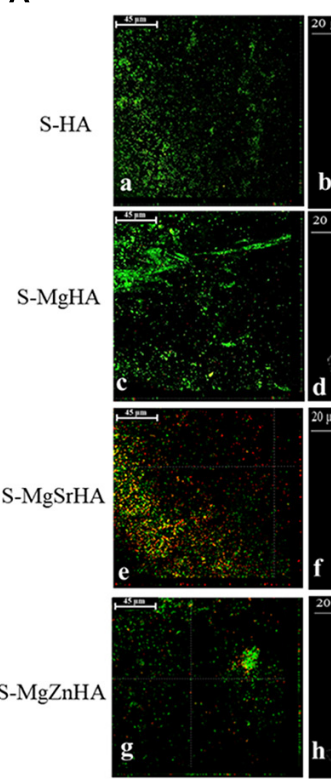

E. coli
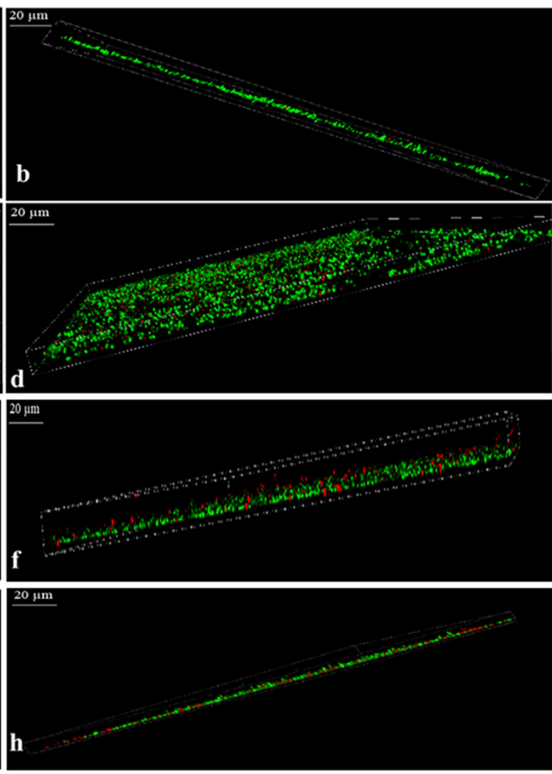

B
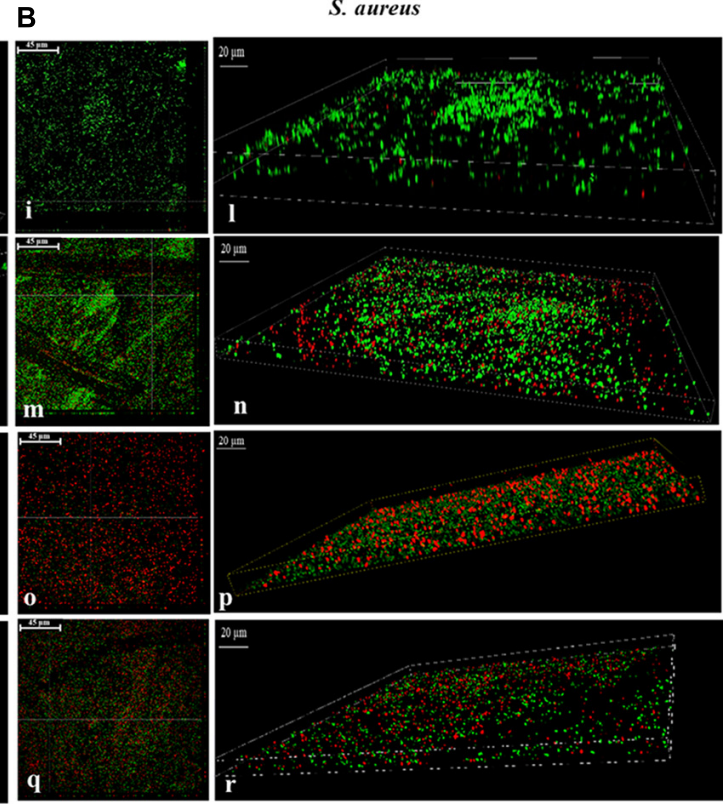

FIGURE 12 | CLSM images of E. coli $\mathbf{( A , a - h )}$ and $\mathbf{S}$. aureus $\mathbf{( B , i - r )}$ adhesion onto apatite samples. The bacterial adhesions of both strains were performed and

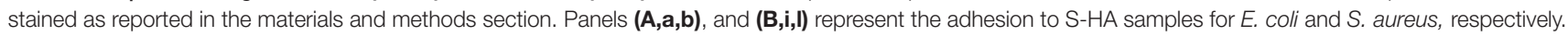
Panels $(\mathbf{A}, \mathbf{c}-\mathbf{h})$ and $\mathbf{( B ,} \mathbf{m}-\mathbf{r})$ refer to the adhesion to ion-doped HA samples for $E$. coli and $S$. aureus, respectively. Orthogonal projections at $40 \times$ magnification for

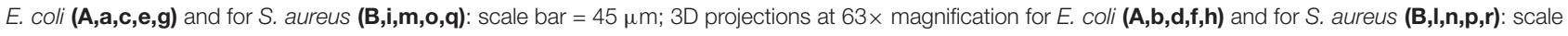
bar $=20 \mu \mathrm{m}$.

as osteopontin (SPP1) and osteonectin (SPARC). These noncollagenous macromolecules are able to stimulate the hASCs to differentiate into the osteoblast cell lineage and are the structural basis for the formation of the bone-implant interface in vivo, which is a key aspect to achieve substantial osteointegration (Shah et al., 2019).

Concerning the antimicrobial ability, our results clearly show that the sintered materials presenting higher solubility, that is, $\mathrm{S}-\mathrm{MgSrHA}$ and $\mathrm{S}-\mathrm{MgZnHA}$, are also the most effective in contrasting the viability of microbial strains. In this respect, an important parameter to consider regarding bacterial proliferation (Andrés et al., 2018) and adhesion (Sheng et al., 2008) is the $\mathrm{pH}$. Our findings regarding the alkaline $\mathrm{pH}$ of S-MgSrHA and the neutral one of the other samples, are in accordance to literature because previous studies reported the increase of $\mathrm{pH}$ of bacterial culture medium as induced by materials containing $\mathrm{Sr}^{2+}$, which contribute to antibacterial effect (Douglas et al., 2018). A recent study reported that $\mathrm{Sr}^{2+}$ is released from surfaces when in contact with fluids. Once released it is an activator of the osteoblasts because it activates calcium receptors: it can positively contribute to reduce the risk of bacterial colonization by promoting an early adhesion of the osteoblasts and can also counteract the cytotoxic effect of other ions such as $\mathrm{Ag}$ (Cochis et al., 2020) or Mg (Gao et al., 2019), whether the Sr is a co-dopant element. For this excellent property of promoting bone growth, thus inhibiting osteoclasts activity, it can be involved in the treatment of osteoporosis (Frasnelli et al., 2017).
Previous studies pointed out that specific ion doping in the structure of nanocrystalline HA enhances the anti-infective character, thanks to the activation of mechanisms increasing the surface charge and ion mobility (Sprio et al., 2019). It was also observed that low crystallinity is particularly desired to obtain effective anti-proliferative ability, particularly against Gram + bacteria (Wu et al., 2018). The present work shows that these physicochemical effects and related biofunctionalities are found also in our sintered CaPs, in spite the high-temperature treatment caused the loss of nanocrystallinity with grain growth from the nano- to the micron size. Indeed, the presence of doping ions in HA powders yielded, after sintering, the formation of a secondary, bioresorbable, $\beta$ TCP phase with increased solubility that can be tailored by the type and extent of initial ion doping. Since no release of $\mathrm{Sr}^{2+}$ was observed, we can conclude that in our tests $\mathrm{Sr}^{2+}$ ions did not come in direct contact with bacteria, so they are supposed to elicit no direct effects on the biologic properties of S-MgSrHA, but rather they were relevant to induce finer microstructure and more intense $\mathrm{Ca}^{2+}$ and $\mathrm{Mg}^{2+}$ ions release, a phenomenon recently found as a trigger of antibacterial ability (Sprio et al., 2019). Regarding S-MgZnHA, also in this material the co-doping with $\mathrm{Mg}^{2+}$ and $\mathrm{Zn}^{2+}$ caused a strong grain size reduction that favored the most intense release of $\mathrm{Ca}^{2+}$ and $\mathrm{Mg}^{2+}$ ions. Since the detected $\mathrm{Zn}$ release is very little and limited in time, we can suppose that, even in very small amounts, the release of $\mathrm{Zn}^{2+}$, previously reputed as a specific antibacterial agent (Thian et al., 2013), played a role in reducing bacterial viability, particularly effective with $E$. coli. The different effect 
in S. aureus and E. coli is due to the nature of the cell wall of Gram positive and negative bacteria, and these results are in accordance with literature. Gram positive have a thick cell wall, because of the presence of 20-25 layers of peptidoglycan, whereas Gram negative have up to three layers, which are between two membranes (the outer and the inner) (Elander, 2003). Hence, $S$. aureus has a negatively charged cell wall, due to lipoteichoic and teichuronic acids (Bari et al., 2017), which attract positively charges present in HA. By contrast, E. coli expose a highly organized compact structure, which is permeable to charged, uncharged, and small molecules. The consequence of these interactions is cell apoptosis via protein denaturation and cell membrane disruption (Bari et al., 2017). Indeed, our antibacterial data showed how these scaffolds are more effective against E. coli than $S$. aureus because Gram negative are more penetrable for their thin peptidoglycan. In this respect, it is worthy to note that, in comparison with the single-doped S-MgHA, the multi-doped S-MgSrHA and S-MgZnHA materials were found to greatly reduce the viability of Gram negative bacterium.

Resuming, our results report that physicochemical aspects such as ion release ability and microstructure of sintered calcium phosphates are biologically relevant factors and can be tailored by specific ion doping. In particular, we found that, in comparison with the single-doped S-MgHA, the bioactive effects are strengthened by synergistic contribution given by the co-doping with $\mathrm{Sr}^{2+}$ and $\mathrm{Zn}^{2+}$ ions. Since $\mathrm{HA}$ and $\beta$ tricalcium phosphate phases can host a very high number of ionic species into their lattice, with consequent alteration of physicochemical properties, the present work suggests that the exploration of different doping agents for $\mathrm{CaP}$ phases can yield new sintered materials with optimized biologic performance.

The integrability of osteosynthesis media with the surrounding bone is a primary target in order to ensure stabilization of fractures or of bone implants. Contrary to bioinert ceramic materials unable to establish tight bonding with bone, the good osteogenic and antibacterial ability shown by the sintered CaPs can help to provide strong and more stable biointerfaces, thus lowering the risk of failure. On the other hand, the alteration of the microstructure induced by multiple ion substitutions can help to improve the mechanical properties, thanks to residual stresses induced by ion doping that can reinforce the flexural strength of ceramics-while retaining compressive strength in the range of cortical bone-and be also beneficial for improving the fatigue life (Hearn, 2013; Bao et al., 2019).

\section{CONCLUSION}

HA powders doped with $\mathrm{Mg}^{2+}, \mathrm{Sr}^{2+}$, and $\mathrm{Zn}^{2+}$ ions were synthesized and sintered to obtain consolidated bulk materials. We found that ion doping in the HA structure can specifically affect the phase composition and microstructure of HA/ $\beta$ TCP composites, formed during the sintering process. This phenomenon enhances flexural strength and resistance to biofilm formation, in respect to the undoped sintered HA, while retaining upmodulation of various genes involving in osteogenesis. Thanks to the good solubility of many different ionic species in the crystal of bioactive calcium phosphates, the present results suggest that ion doping in sintered calcium phosphates can be designed to obtain tailored composition, microstructure, optimized mechanical properties, and ion release profile, capable to express good osteogenic ability and to achieve optimized eukaryotic vs. prokaryotic cell selectivity. These are biofunctionalities that, co-existing in the same device, are key aspects in favoring osteointegration and enhanced resistance against infections, and they are among the most critical threads in bone surgery. Hence, the obtained results open to the possibility of developing new biodevices, such as plates or screws and other osteosynthesis media with enhanced performance, are suitable for more effective and safer therapies in support of bone surgery procedures.

\section{DATA AVAILABILITY STATEMENT}

The raw data supporting the conclusions of this article will be made available by the authors, without undue reservation.

\section{AUTHOR CONTRIBUTIONS}

MD, LP, EM, and ER were responsible for the conduction of experiments and data acquisition. SS, FM, and MI were responsible for data interpretation. SS, MT, NP, LV, and AT were responsible for conceptualization, design, and supervision of the study. SS, MD, EM, and LV were responsible for manuscript writing and editing. NP, LV, and AT were responsible for funding acquisition. All authors have read and approved the final manuscript.

\section{FUNDING}

The experiments carried out at the University of Ferrara were supported by grants from FESR POR Regione Emilia Romagna Niprogen project, local unit MT and MIUR PRIN 2017 C8RYSS project, national unit FM, respectively. The study was supported by a grant of the Italian Ministry of Education, University and Research (MIUR) to the Department of Molecular Medicine of the University of Pavia under the initiative "Dipartimenti di Eccellenza (2018-2022)." NP is supported by the European Commission under the FET Proactive ("Neurofibres") grant No. 732344, as well as by the Italian Ministry of Education, University and Research (MIUR) under the ARS01-01384-PROSCAN and the PRIN-20177TTP3S grants.

\section{ACKNOWLEDGMENTS}

The authors are grateful to Prof. R. Migliavacca (Department of Clinical-Surgical Diagnostic and Pediatric Sciences, Unit of Microbiology and Clinical Microbiology, University of Pavia, Italy), for providing E. coli and S. aureus bacteria. 


\section{REFERENCES}

Albers, C. E., Hofstetter, W., Siebenrock, K. A., Landmann, R., and Klenke, F. M. (2013). In vitro cytotoxicity of silver nanoparticles on osteoblasts and osteoclasts at antibacterial concentrations. Nanotoxicology 7, 30-36. doi: 10 . 3109/17435390.2011.626538

Alexander, R., and Theodos, L. (1993). Fracture of the bone-grafted mandible secondary to stress shielding: report of a case and review of the literature. J. Oral Maxillofac. Surg. 51, 695-697. doi: 10.1016/s0278-2391(10)80273-3

Andrés, N. C., Sieben, J. M., Baldini, M., Rodríguez, C. H., Famiglietti, A., and Messina, P. V. (2018). Electroactive $\mathrm{Mg}(2+)$-hydroxyapatite nanostructured networks against drug-resistant bone infection strains. ACS Appl. Mater Interf. 10, 19534-19544. doi: 10.1021/acsami.8b06055

Ballardini, A., Montesi, M., Panseri, S., Vandini, A., Balboni, P. G., Tampieri, A., et al. (2018). New hydroxyapatite nanophases with enhanced osteogenic and anti-bacterial activity. J. Biomed. Mater. Res. A 106, 521-530. doi: 10.1002/jbm. a.36249

Bao, Y., Kuang, F., Sun, Y., Li, Y., Wan, D., Shen, Z., et al. (2019). A simple way to make pre-stressed ceramics with high strength. J. Mater. 5, 657-662. doi: 10.1016/j.jmat.2019.06.001

Bari, A., Bloise, N., Fiorilli, S., Novajra, G., Vallet-Regi, M., Bruni, G., et al. (2017). Copper-containing mesoporous bioactive glass nanoparticles as multifunctional agent for bone regeneration. Acta Biomater. 55, 493-504. doi: 10.1016/j.actbio.2017.04.012

Bertinetti, L., Drouet, C., Combes, C., Rey, C., Tampieri, A., Coluccia, S., et al. (2009). Surface Characteristics of Nanocrystalline apatites: effect of $\mathrm{Mg}$ surface enrichment on morphology, surface hydration species, and cationic environments. Langmuir 25, 5647-5654. doi: 10.1021/la804230j

Bigi, A., Foresti, E., Gandolfi, M., Gazzano, M., and Roveri, N. (1997). Isomorphous substitutions in $\beta$-tricalcium phosphate: the different effects of zinc and strontium. J. Inorgan. Biochem. 66, 259-265. doi: 10.1016/s0162-0134(96) 00219-x

Bigi, A., Foresti, E., Gregorini, R., Ripamonti, A., Roveri, N., and Shah, J. S. (1992). The role of magnesium on the structure of biological apatites. Calcif. Tissue Intern. 50, 439-444. doi: 10.1007/bf00296775

Boanini, E., Gazzano, M., and Bigi, A. (2010). Ionic substitutions in calcium phosphates synthesized at low temperature. Acta Biomater. 6, 1882-1894. doi: 10.1016/j.actbio.2009.12.041

Boanini, E., Gazzano, M., Nervi, C., Chierotti, M. R., Rubini, K., Gobetto, R., et al. (2019). Strontium and zinc substitution in beta-tricalcium phosphate: an X-ray diffraction, solid state NMR and ATR-FTIR study. J. Funct. Biomater. 10:20. doi: $10.3390 /$ jfb10020020

Capuccini, C., Torricelli, P., Boanini, E., Gazzano, M., Giardino, R., and Bigi, A. (2009). Interaction of Sr-doped hydroxyapatite nanocrystals with osteoclast and osteoblast-like cells. J. Biomed. Mater. Res. A 89, 594-600. doi: 10.1002/jbm.a. 31975

Cazalbou, S., Eichert, D., Ranz, X., Drouet, C., Combes, C., Harmand, M. F., et al. (2005). Ion exchanges in apatites for biomedical application. J. Mater. Sci. Mater. Med. 16, 405-409. doi: 10.1007/s10856-005-6979-2

Cochis, A., Barberi, J., Ferraris, S., Miola, M., Rimondini, L., Vernè, E., et al. (2020). Competitive surface colonization of antibacterial and bioactive materials doped with strontium and/or silver ions. Nanomaterials 10:120. doi: 10.3390/ nano 10010120

Dalby, M. J., Gadegaard, N., and Oreffo, R. O. (2014). Harnessing nanotopography and integrin-matrix interactions to influence stem cell fate. Nat. Mater. 13, 558-569. doi: 10.1038/nmat3980

Docheva, D., Popov, C., Alberton, P., and Aszodi, A. (2014). Integrin signaling in skeletal development and function. Birth Def. Res. C Embryo Today 102, 13-36. doi: 10.1002/bdrc.21059

Douglas, T. E. L., Dziadek, M., Gorodzha, S., Lišková, J., Brackman, G., Vanhoorne, V., et al. (2018). Novel injectable gellan gum hydrogel composites incorporating $\mathrm{Zn}$ - and Sr-enriched bioactive glass microparticles: high-resolution X-ray microcomputed tomography, antibacterial and in vitro testing. J. Tissue Eng. Regen. Med. 12, 1313-1326. doi: 10.1002/term.2654

Dutta, S. R., Passi, D., Singh, P., and Bhuibhar, A. (2015). Ceramic and non-ceramic hydroxyapatite as a bone graft material: a brief review. Iran. J. Med. Sci. 184, 101-106. doi: 10.1007/s11845-014-1199-8
Elander, R. P. (2003). "Industrial microbiology: an introduction," in The Quarterly Review of Biology, eds M. J. Waites, N. L. Morgan, J. S. Rockey, and G. Higton (Chicago, IL: University of Chicago Press), 96.

Eliaz, N., and Metoki, N. (2017). Calcium phosphate bioceramics: a review of their history, structure, properties, coating technologies and biomedical applications. Materials 10:334. doi: 10.3390/ma10040334

Frasnelli, M., Cristofaro, F., Sglavo, V. M., Dirè, S., Callone, E., Ceccato, R., et al. (2017). Synthesis and characterization of strontium-substituted hydroxyapatite nanoparticles for bone regeneration. Mater. Sci. Eng. C 71, 653-662. doi: 10.1016/j.msec.2016.10.047

Gao, Z., Song, M., Liu, R.-L., Shen, Y., Ward, L., Cole, I., et al. (2019). Improving in vitro and in vivo antibacterial functionality of $\mathrm{Mg}$ alloys through microalloying with Sr and Ga. Mater. Sci. Eng. C 104:109926. doi: 10.1016/j.msec. 2019.109926

Giannini, C., Ladisa, M., Altamura, D., Siliqi, D., Sibillano, T., and De Caro, L. (2016). X-ray diffraction: a powerful technique for the multiple-length-scale structural analysis of nanomaterials. Crystals 6:87. doi: 10.3390/cryst6080087

Goodrich, J., Sandler, A., and Tepper, O. (2012). A review of reconstructive materials for use in craniofacial surgery bone fixation materials, bone substitutes, and distractors. Child's Nerv. Syst. 28, 1577-1588. doi: 10.1007/ s00381-012-1776-y

Griffith, A. A. (1921). VI. The phenomena of rupture and flow in solids. Philos. Trans. R. Soc. Lond. A 221, 163-198. doi: 10.1098/rsta.1921.0006

Hankenson, K. D., Hormuzdi, S. G., Meganck, J. A., and Bornstein, P. (2005). Mice with a disruption of the thrombospondin 3 gene differ in geometric and biomechanical properties of bone and have accelerated development of the femoral head. Mol. Cell Biol. 25, 5599-5606. doi: 10.1128/mcb.25.13.5599-5606. 2005

Hearn, E. J. (2013). Mechanics of Materials: An Introduction to the Mechanics of Elastic and Plastic Deformation of Solids and Structural Components. Amsterdam: Elsevier.

Henriques Lourenço, A., Neves, N., Ribeiro-Machado, C., Sousa, S. R., Lamghari, M., Barrias, C. C., et al. (2017). Injectable hybrid system for strontium local delivery promotes bone regeneration in a rat critical-sized defect model. Sci. Rep. 7:5098.

Hofer, U. (2019). The cost of antimicrobial resistance. Nat. Rev. Microbiol. 17:3.

Huang, M., Li, T., Pan, T., Zhao, N., Yao, Y., Zhai, Z., et al. (2016). Controlling the strontium-doping in calcium phosphate microcapsules through yeast-regulated biomimetic mineralization. Regen. Biomater. 3, 269-276. doi: 10.1093/rb/ rbw025

Kannan, S., Pina, S., and Ferreira, J. M. F. (2006). Formation of strontium-stabilized $\beta$-tricalcium phosphate from calcium-deficient apatite. Science 89, 3277-3280. doi: 10.1111/j.1551-2916.2006.01203.x

Keaveny, T. M., and Hayes, W. C. (1993). "Mechanical properties of cortical and trabecular bone," in Bone, ed. B. K. Hall (Boca Raton, FL: CRC Press), 285-344.

Khan, P. K., Mahato, A., Kundu, B., Nandi, S. K., Mukherjee, P., Datta, S., et al. (2016). Influence of single and binary doping of strontium and lithium on in vivo biological properties of bioactive glass scaffolds. Sci. Rep. 6:32964.

Li, B., and Webster, T. J. (2018). Bacteria antibiotic resistance: new challenges and opportunities for implant-associated orthopedic infections. J. Orthop. Res. 36, 22-32.

Liu, W., Huan, Z., Xing, M., Tian, T., Xia, W., Wu, C., et al. (2019). Strontiumsubstituted dicalcium silicate bone cements with enhanced osteogenesis potential for orthopaedic applications. Materials 12:2276. doi: 10.3390/ ma12142276

Manfrini, M., Di Bona, C., Canella, A., Lucarelli, E., Pellati, A., D’agostino, A., et al. (2013). Mesenchymal stem cells from patients to assay bone graft substitutes. J. Cell Physiol. 228, 1229-1237. doi: 10.1002/jcp.24276

Mazzoni, E., D’agostino, A., Iaquinta, M. R., Bononi, I., Trevisiol, L., Rotondo, J. C., et al. (2020). Hydroxylapatite-collagen hybrid scaffold induces human adiposederived mesenchymal stem cells to osteogenic differentiation in vitro and bone regrowth in patients. Stem Cells Transl. Med. 9, 377-388. doi: 10.1002/sctm.190170

Mazzoni, E., D’agostino, A., Manfrini, M., Maniero, S., Puozzo, A., Bassi, E., et al. (2017). Human adipose stem cells induced to osteogenic differentiation by an innovative collagen/hydroxylapatite hybrid scaffold. FASEB J. 31, 4555-4565. doi: 10.1096/fj.201601384r 
Mazzoni, E., Rigolin, G. M., Alaribe, F. N., Pancaldi, C., Maniero, S., Comar, M., et al. (2012). Simian virus 40 efficiently infects human T lymphocytes and extends their lifespan. Exp. Hematol. 40, 466-476. doi: 10.1016/j.exphem.2012. 02.008

Montesi, M., Panseri, S., Dapporto, M., Tampieri, A., and Sprio, S. (2017). Sr-substituted bone cements direct mesenchymal stem cells, osteoblasts and osteoclasts fate. PLoS One 12:e0172100. doi: 10.1371/journal.pone.01 72100

Munch, E., Franco, J., Deville, S., Hunger, P., Saiz, E., and Tomsia, A. P. (2008). Porous ceramic scaffolds with complex architectures. JOM 60, 54-58. doi: 10.1007/s11837-008-0072-5

Paiva, K. B. S., and Granjeiro, J. M. (2017). Matrix metalloproteinases in bone resorption. Remodel. Repair. Prog. Mol. Biol. Transl. Sci. 148, 203-303. doi: 10.1016/bs.pmbts.2017.05.001

Pallavicini, P., Arciola, C. R., Bertoglio, F., Curtosi, S., Dacarro, G., D’agostino, A., et al. (2017). Silver nanoparticles synthesized and coated with pectin: an ideal compromise for anti-bacterial and anti-biofilm action combined with woundhealing properties. J. Coll. Interf. Sci. 498, 271-281. doi: 10.1016/j.jcis.2017.03. 062

Pohler, O. E. M. (2002). "Failures of metallic orthopedic implants[1]," in Failure Analysis and Prevention, eds W. T. Becker and R. J. Shipley (Cleveland, OH: ASM International).

Polo-Corrales, L., Latorre-Esteves, M., and Ramirez-Vick, J. E. (2014). Scaffold design for bone regeneration. J. Nanosci. Nanotechnol. 14, 15-56.

Procopio, A., Malucelli, E., Pacureanu, A., Cappadone, C., Farruggia, G., Sargenti, A., et al. (2019). Chemical fingerprint of $\mathrm{Zn}$-hydroxyapatite in the early stages of osteogenic differentiation. ACS Cent. Sci. 5, 1449-1460. doi: 10.1021/acscentsci. $9 \mathrm{~b} 00509$

Ribeiro, M., Monteiro, F. J., and Ferraz, M. P. (2012). Infection of orthopedic implants with emphasis on bacterial adhesion process and techniques used in studying bacterial-material interactions. Biomatter 2, 176-194. doi: 10.4161/ biom.22905

Rodríguez-Lorenzo, L. M., Hart, J. N., and Gross, K. A. (2003). Structural and Chemical Analysis of Well-Crystallized Hydroxyfluorapatites. J. Phys. Chem. B 107, 8316-8320. doi: 10.1021/jp027556o

Sasaki, S., Fujino, K., Tak, E., and Uchi, Y. (1979). X-Ray determination of electrondensity distributions in oxides, $\mathrm{MgO}, \mathrm{MnO}, \mathrm{CoO}$, and $\mathrm{NiO}$, and atomic scattering factors of their constituent atoms. Proc. Jpn. Acad. Ser. B 55, 43-48. doi: $10.2183 /$ pjab.55.43

Schroeder, L. W., Dickens, B., and Brown, W. E. (1977). Crystallographic studies of the role of $\mathrm{Mg}$ as a stabilizing impurity in $\beta$-Ca3(PO4)2. II. refinement of $\mathrm{Mg}$ containing $\beta$-Ca3(PO4)2. J. Solid State Chem. 22, 253-262. doi: 10.1016/00224596(77)90002-0

Shah, F. A., Thomsen, P., and Palmquist, A. (2019). Osseointegration and current interpretations of the bone-implant interface. Acta Biomater. 84, 1-15. doi: 10.1016/j.actbio.2018.11.018

Sheikh, Z., Najeeb, S., Khurshid, Z., Verma, V., Rashid, H., and Glogauer, M. (2015). Biodegradable materials for bone repair and tissue engineering applications. Materials 8, 5744-5794. doi: 10.3390/ma8095273

Sheng, X., Ting, Y. P., and Pehkonen, S. O. (2008). The influence of ionic strength, nutrients and $\mathrm{pH}$ on bacterial adhesion to metals. J. Colloid Interf. Sci. 321, 256-264. doi: 10.1016/j.jcis.2008.02.038
Slavin, Y. N., Asnis, J., Hafeli, U. O., and Bach, H. (2017). Metal nanoparticles: understanding the mechanisms behind antibacterial activity. J. Nanobiotechnol. 15:65.

Sprio, S., Preti, L., Montesi, M., Panseri, S., Adamiano, A., Vandini, A., et al. (2019). Surface phenomena enhancing the antibacterial and osteogenic ability of nanocrystalline hydroxyapatite, activated by multiple-ion doping. ACS Biomater. Sci. Eng. 5, 5947-5959. doi: 10.1021/acsbiomaterials.9b00893

Sprio, S., Tampieri, A., Landi, E., Sandri, M., Martorana, S., Celotti, G., et al. (2008). Physico-chemical properties and solubility behaviour of multi-substituted hydroxyapatite powders containing silicon. Mater. Sci. Eng. C 28, 179-187. doi: 10.1016/j.msec.2006.11.009

Suryavanshi, A., Borse, V., Pawar, V., Kotagudda Ranganath, S., and Srivastava, R. (2016). Material advancements in bone-soft tissue fixation devices. Sci. Adv. Today 2, 25236.

Tampieri, A., Celotti, G. C., Landi, E., and Sandri, M. (2004). Magnesium doped hydroxyapatite: synthesis and characterization. Key Eng. Mater. 264-268, 20512054. doi: 10.4028/www.scientific.net/kem.264-268.2051

Thian, E. S., Konishi, T., Kawanobe, Y., Lim, P. N., Choong, C., Ho, B., et al. (2013). Zinc-substituted hydroxyapatite: a biomaterial with enhanced bioactivity and antibacterial properties. J. Mater. Sci. Mater. Med. 24, 437-445. doi: 10.1007/ s10856-012-4817-x

von der Mark, K., Park, J., Bauer, S., and Schmuki, P. (2010). Nanoscale engineering of biomimetic surfaces: cues from the extracellular matrix. Cell Tissue Res. 339, 131-153. doi: 10.1007/s00441-009-0896-5

Wu, C., Ramaswamy, Y., Kwik, D., and Zreiqat, H. (2007). The effect of strontium incorporation into $\mathrm{CaSiO} 3$ ceramics on their physical and biological properties. Biomaterials 28, 3171-3181. doi: 10.1016/j.biomaterials.2007.04.002

Wu, V. M., Tang, S., and Uskokovic, V. (2018). Calcium phosphate nanoparticles as intrinsic inorganic antimicrobials: the antibacterial effect. ACS Appl. Mater. Interf. 10, 34013-34028. doi: 10.1021/acsami.8b12784

Yashima, M., Sakai, A., Kamiyama, T., and Hoshikawa, A. (2003). Crystal structure analysis of $\beta$-tricalcium phosphate $\mathrm{Ca} 3(\mathrm{PO} 4) 2$ by neutron powder diffraction. J. Solid State Chem. 175, 272-277. doi: 10.1016/s0022-4596(03)00279-2

Zima, A., Ślósarczyk, A., Paszkiewicz, Z., Staszewska, M., Mróz, W., and Chróścicka, A. (2011). Effects of Mg additives on properties of Mg-doped hydroxyapatite ceramics. Adv. Sci. Technol. 76, 60-65. doi: 10.4028/www. scientific.net/ast.76.60

Zreiqat, H., Ramaswamy, Y., Wu, C., Paschalidis, A., Lu, Z., James, B., et al. (2010). The incorporation of strontium and zinc into a calcium-silicon ceramic for bone tissue engineering. Biomaterials 31, 3175-3184. doi: 10.1016/j. biomaterials.2010.01.024

Conflict of Interest: The authors declare that the research was conducted in the absence of any commercial or financial relationships that could be construed as a potential conflict of interest.

Copyright (C) 2020 Sprio, Dapporto, Preti, Mazzoni, Iaquinta, Martini, Tognon, Pugno, Restivo, Visai and Tampieri. This is an open-access article distributed under the terms of the Creative Commons Attribution License (CC BY). The use, distribution or reproduction in other forums is permitted, provided the original author(s) and the copyright owner(s) are credited and that the original publication in this journal is cited, in accordance with accepted academic practice. No use, distribution or reproduction is permitted which does not comply with these terms. 